\title{
Two-Phase Fluidized Bed Model for Pressurized Carbonation Kinetics of Calcium Oxide
}

\author{
Joseph G. Yao, ${ }^{1, *}$ Zili Zhang, ${ }^{1}$ Mark Sceats, ${ }^{2}$ Geoffrey C. Maitland, ${ }^{1}$ and Paul S. Fennell ${ }^{1,3, *}$ \\ ${ }^{1}$ Imperial College London, South Kensington, Exhibition Road London, UK, SW7 2AZ \\ ${ }^{2}$ Calix Limited, Level 1, 9 Bridge Street, Pymble, Australia, NSW 2073 \\ ${ }^{3}$ Currently vising affiliate at Joint Bioenergy Institute, 5885 Hollis St. Emeryville, CA 94608, USA \\ Keywords: Calcium Looping, Carbonation, Fluidized Bed, Two-Phase Model, Pressurized, Modelling
}

\begin{abstract}
A two-phase reactor model has been developed using a system of ordinary differential equations in MATLAB to model the carbonation reaction and therefore determine the kinetics of calcium oxide in a pressurised fluidised bed reactor as part of the calcium looping cycle. The model assumes that the particulate and bubble phases are modelled as a CSTR and a PFR respectively. The random pore model developed by Bhatia and Perlmutter ${ }^{1}$ is incorporated into the system of equations to predict the rate of carbonation for pressures up to 5 bara total, and $\mathrm{CO}_{2}$ partial pressures up to $150 \mathrm{kPa}$. The surface rate constant and product layer diffusivity in the random pore model expression were obtained by fitting the model to experimental data for a range of pressures, $\mathrm{CO}_{2}$ concentrations and temperatures by minimization of the residual sum of squares. The surface rate constants were found to be between 3.05 and $12.9 \times 10^{-10} \mathrm{~m}^{4} \mathrm{~mol}^{-1} \mathrm{~s}^{-1}$ for a temperature range of 550 to 750 ${ }^{\circ} \mathrm{C}$. The product layer diffusivities were found to be between 0.06 and $23.6 \times 10^{-13} \mathrm{~m}^{2} \mathrm{~s}^{-1}$ for the same temperature range. The surface rate constant and product layer diffusivity activation energy were calculated using the Arrhenius equation and was found to be approximately $48 \pm 17 \mathrm{~kJ} \mathrm{~mol}^{-1}$ and $196 \pm 43 \mathrm{~kJ} \mathrm{~mol}^{-1}$ respectively.
\end{abstract}

\section{INTRODUCTION}

Calcium looping is a promising carbon capture technology which has reached the pilot scale. ${ }^{2,3}$ The process utilises the reversible reaction between calcium oxide $(\mathrm{CaO})$ and carbon dioxide $\left(\mathrm{CO}_{2}\right)$ to capture $\mathrm{CO}_{2}$ from point-source emissions such as a power station. . $^{47}$ Two reactors are typically required for the process. The first reactor, known as the carbonator (which operates at $650{ }^{\circ} \mathrm{C}$ ), contains $\mathrm{CaO}$-based sorbent, which reacts with the $\mathrm{CO}_{2}$ within the flue gas inlet stream. This reaction is called carbonation. The product, calcium carbonate $\left(\mathrm{CaCO}_{3}\right)$, is then cycled to the second reactor, the calciner. In the calciner, which operates at temperatures around $900{ }^{\circ} \mathrm{C}$, the $\mathrm{CaCO}_{3}$ decomposes back into $\mathrm{CaO}$ and $\mathrm{CO}_{2}$. This achieves two results. Firstly, the sorbent is regenerated and can be cycled back to the carbonator, and secondly a high-purity $\mathrm{CO}_{2}$ outlet stream is produced which can be taken away for storage.

It is well known that the carbonation reaction of calcium oxide is split into two distinct regimes. ${ }^{2}$ The first step is kinetically controlled, and involves a fast heterogeneous reaction which occurs on the particle surface. The second stage is diffusion controlled. The reaction becomes significantly slower as there are diffusion limitations owing to the formation of a product layer of $\mathrm{CaCO}_{3}$ on the particle surface.
This product layer acts as an extra barrier which the $\mathrm{CO}_{2}$ must diffuse through to reach the reaction site. Consequently, the conversion will eventually plateau. Lee ${ }^{8}$ suggested that the difficulty in approaching complete conversions is attributable to unfavourable initial pore size distributions. Bhatia and Perlmutter ${ }^{1}$ postulated that the conversion reaches a ceiling as the smaller pores dominate the reaction, and that the small pores are more likely to close up owing to the formation of $\mathrm{CaCO}_{3}$, which has a greater molar volume than $\mathrm{CaO}$. As a result, the conversion becomes restricted to the larger pores in which reaction occurs more slowly.

There have been many proposed mechanisms and models of the carbonation reaction mechanism.1, 8-11 The shrinking core and progressive conversion models are frequently used for non-catalytic gas-solid reactions. ${ }^{12,13}$ The shrinking core model, which visualises a reaction front that first occurs on the outer surface of the particle and then moves inwards leaving behind completely converted material, has been applied to the carbonation reaction by Lee. ${ }^{8}$ The main limitation of the shrinking core model is that it was designed for non-porous solids and predicts complete conversion at infinite time. Therefore, it is not directly applicable to the carbonation reaction. The progressive conversion model, on the other hand, models the reactant entering and 
rapidly diffusing throughout the particle. Thus, the reactant converts continuously and progressively through the particle. Although the progressive conversion model can be applied to porous materials, it makes the assumption that the characteristic time for diffusion into the particle is negligible compared to the reaction: This means it cannot be applied to the diffusion-controlled step. ${ }^{14}$

In consequence of the above, there has been a significant emphasis on modelling the carbonation of $\mathrm{CaO}$ with either the grain model or the random pore model. ${ }^{15}$ The grain model visualises a particle which is composed of grains that are surrounded by pores through which the gas can diffuse through to reach the grain surface. It has been applied to the carbonation process by many researchers. ${ }^{9}, 14,16$ Khoshandam et al. ${ }^{16}$ applied a grain model to the data presented in a paper by Bhatia and Perlmutter. ${ }^{1}$ The authors modelled the carbonation reaction in two sections. The first section accounted for both kinetic- and diffusion- control effects whereas the latter only focused on the diffusion-controlled reaction. They fitted the model to experiments carried out at $400-750{ }^{\circ} \mathrm{C}$ and obtained acceptable fits. The authors reported that the model was more capable of predicting behaviour at higher temperatures as the onset of diffusion effects occurred earlier. They concluded that the porosity of the sorbent played the most important role in their model for determining conversion behaviour. Stendardo and Foscolo $^{14}$ developed a grain model which incorporated a variable diffusion coefficient for the gaseous reactant through the product layer as it formed. Their model was used to describe the carbonation of dolomite and was shown to have good agreement with their experimental data. However, the work was confined to cycling over a single set of conditions so its applicability to predict the reactions under different temperatures has not been verified.

The other popular model, the random pore model, was developed by Bhatia and Perlmutter. ${ }^{17,18}$ Although it was initially designed for the sulfation of $\mathrm{CaO}$, it was applicable to the carbonation reaction as well. The model visualises the pore structure as a network of randomly arranged cylindrical pores of uniform size. The initial reaction occurs on the boundary of the pores forming a product layer of $\mathrm{CaCO}_{3}$. Due to the formation and accumulation of the product layer, the reaction surface begins to grow. However, at later stages, the growing surfaces begin to intersect one another, leading to a reduction in the surface area. One major advantage of the model is that it can forecast the reaction surface area at any conversion as a function of the initial pore structure. Several researchers ${ }^{1,10,19}$ have implemented this model to describe the conversion of $\mathrm{CaO}$ during either carbonation or sulfation over time but have not linked their results to a dynamic simulation. Furthermore, most of these modelling attempts have been based on the results from TGA experiments. Grasa et al. ${ }^{10}$ used the random pore model to determine the intrinsic kinetics of calcium cycling experiments in a TGA. The authors were able to predict the conversion profile over time for a range of different temperatures. Activation energies of 19.2 and $21.3 \mathrm{~kJ} \mathrm{~mol}^{-1}$ were obtained for their Katowice and Imeco limestones, respectively, for the kinetically-controlled part of the reaction. The pre-exponential factors were approximately $5 \times 10^{-9} \mathrm{~m}^{4} \mathrm{~mol}^{-1} \mathrm{~s}^{-1}$. At the higher conversions, the researchers reported a significantly higher mean activation energy of $163 \mathrm{~kJ} \mathrm{~mol}^{-1}$ and pre-exponential factor around $4 \times 10^{-6} \mathrm{~m}^{2} \mathrm{~s}^{-1}$. Nouri et al. ${ }^{19}$ modified the random pore model to include the effects of bulk flow by introducing a concentration rate function. The authors applied their model to the TGA data obtained by other researchers, namely Bhatia and Perlmutter ${ }^{1}$ and Grasa et al. ${ }^{10}$. However, despite a good fit to the conversion vs time data by Bhatia and Perlmutter ${ }^{1}$, the model did not fit the kinetically-controlled part of the data from Grasa et al. ${ }^{10}$ Nouri et al. ${ }^{19}$ suggested that the poor fit was caused by the macroporous texture of the $\mathrm{CaO}$ sorbents they used. In addition to this, the authors reported that the Langmuir-Hinshelwood rate expression demonstrated the most accuracy for predicting the experimental data and that the product layer diffusion could be expressed as an exponential function. Furthermore, they postulated that ionic solid phase diffusion is dominant in the product layer based on the low values of the diffusivity and high activation energies that they estimated.

Currently, only gas-solid reaction models, which do not consider the reaction environment, have been used to describe the carbonation reaction. There has yet to be any work involving the use of a dynamic (non-steady state) reactor model to predict carbonation kinetics. To this end, this paper looks at a method of applying a combined gas-solid reaction and reactor model to determine the kinetics of pressurised carbonation reactions. A two-phase reactor model developed by $\operatorname{Scott}^{20}$ in MATLAB was used as a starting point. This model was adapted and combined with the random pore model in order to obtain the reaction rate constants for carbonation experiments carried out in a $3 \mathrm{~kW}_{\mathrm{e}}$ bench-scale pressurised fluidised bed reactor.

\section{EXPERIMENTAL SECTION}

Materials. The calcium oxide used in this investigation was prepared from ex situ calcination of natural Longcliffe limestone $\left(\sim 98 \%\right.$ purity $\left.\mathrm{CaCO}_{3}\right)$. Longcliffe limestone, the precursor was calcined inside a horizontal tube furnace (Lenton) at $850^{\circ} \mathrm{C}$ for $30 \mathrm{~min}$. The furnace was heated up at a rate of $60^{\circ} \mathrm{C} \mathrm{min}^{-1}$ under a nitrogen flow of $1.2 \mathrm{~L} \mathrm{~min}^{-1}$. The sample was withdrawn from the tube furnace at around 500 ${ }^{\circ} \mathrm{C}$ and transferred to a desiccator. Once the sample cooled down to ambient temperature, it was then placed in a small plastic vial and sealed with Parafilm $M$. This method was designed to minimize the contact time of the calcined sample with the atmosphere to avoid hydration and slow carbonation from atmospheric $\mathrm{CO}_{2}$. Quality control of the sorbent was carried out by periodically heating up samples from different batches in a TGA (TA Instruments, QR5000 IR) to check the degree of calcination. These tests were carried out by ramping the temperature of the TGA from $110{ }^{\circ} \mathrm{C}$ to 410 ${ }^{\circ} \mathrm{C}$ and then $900{ }^{\circ} \mathrm{C}$ in an inert (nitrogen) atmosphere to measure weight loss due to moisture content, hydration and uncalcined limestone. The properties of the calcined samples are given in Table 1.

The sand (G60 white silica sand- supplied by David Ball Group PLC), sieved to a size fraction of 425-500 $\mu \mathrm{m}$, was used as the inert fluidizing material for the reactor. The size 
Table 1 Properties of calcined Longcliffe limestone.

\begin{tabular}{|c|c|c|c|c|}
\hline $\begin{array}{l}\text { Degree of calcination } \\
(\%)\end{array}$ & BET Surface Area ${ }^{a}\left(m^{2} g^{-1}\right)$ & Porosityb,c & Skeletal Density ${ }^{b, d}\left(\mathrm{~g} \mathrm{~m}^{-3}\right)$ & Envelope Density ${ }^{d}\left(\mathrm{~g} \mathrm{~m}^{-3}\right)$ \\
\hline $96.17 \pm 0.87$ & $19.40 \pm 3.28$ & $0.50 \pm 0.01$ & $3.15 \pm 0.10$ & $1.57 \pm 0.05$ \\
\hline
\end{tabular}

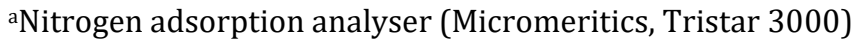

${ }^{\mathrm{b}}$ Mercury Intrusion Porosimetry (Micromeritics, Autopore IV)

cPorosity calculated for pore size $<10 \mu \mathrm{m}$ to exclude interparticle spacing within the tested samples

${ }^{\mathrm{d}}$ Helium pycnometer (Micromeritics, AccuPyc 1330)

fraction of the sand was chosen to be close to that of the calcium oxide to maintain the fluidisation characteristics of the bed.

Experimental Setup. The pressurised fluidised-bed reactor (shown in Figure 1) that was used for this work has been previously reported by Zhang et al. ${ }^{21}$ The reactor was a $30 \mathrm{~mm}$ o.d. and $260 \mathrm{~mm} \mathrm{~L}$ quartz vessel with a $12.5 \mathrm{~mm}$ o.d. mouth at the bottom. The vessel was held inside a 48 mm o.d. Incoloy® Alloy $800 \mathrm{HT}$ cylindrical tube which was sealed on the top and bottom by a set of flanges. The tube was resistance heated with a $3 \mathrm{~kW}_{\mathrm{e}}$ transformer via copper electrodes. K-type thermocouples were used to measure the temperature $10 \mathrm{~cm}$ above the mouth of the quartz liner (bed temperature) and at the wall of the Incoloy tube (wall temperature).

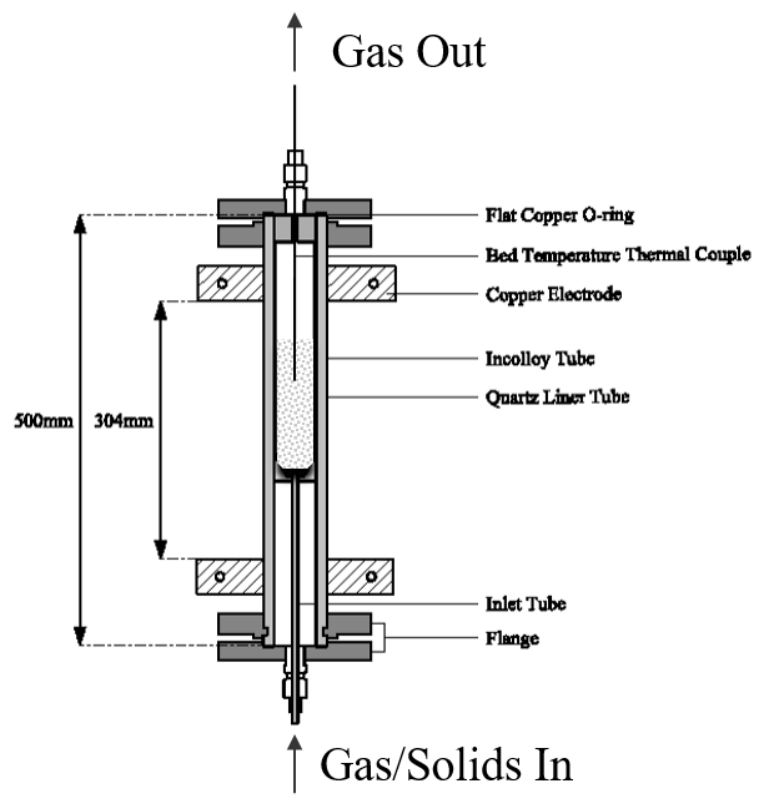

Figure 1 Schematic diagram of the pressurized fluidized-bed reactor (PFBR).

Experimental Procedure. For each experiment, the reactor was leak tested and then heated under $50 \mathrm{ml} \mathrm{s}^{-1}$ of $\mathrm{N}_{2}$ to the desired operating temperature. Sand (50 g) was added into the reactor to form an inert fluidised bed and the fluidizing gas flow rate was increased to $3 U_{m f}$. The analyser was purged with $\mathrm{N}_{2}$ (99.998 vol\% purity supplied by BOC) and a single-point calibration (with 29.89 vol\% calibrationgrade $\mathrm{CO}_{2}$ from BOC) was then carried out. After the calibration, the flow rates of $\mathrm{CO}_{2}$ (from a $99.9 \%$ purity $\mathrm{CO}_{2}$ cylinder supplied by BOC) and $\mathrm{N}_{2}$ was adjusted, using Bronkhorst EL-Flow $®$ Select Series Mass Flow Controllers (MFCs), to give the desired concentration of $\mathrm{CO}_{2}$ (given in Table 2).

The $\mathrm{CaO}$ particles were injected into the reactor through a solid feeding system which functioned like a pressurised lock-hopper. The pressure in the feeding system was controlled using a back-pressure regulator. Prior to each injection, an empty feed (a blank injection of gas with no sample material) was carried out. Here, the feeding system was pressurised to 0.5 bar above the system pressure with $\mathrm{N}_{2}$, and then released into the reactor through a plug valve. The results of the blank feed were important for data analysis as it was important to account for the effects of the injection of pressurised gas along with the reactant. Next, $0.5 \mathrm{~g}$ batches of $\mathrm{CaO}$ were injected into the reactor with the same procedure for the temperature and pressure range highlighted in Table 2. A MGA3000C IR gas analyser (ADC Gas Analysis) was used to sample the off-gas from the reactor. The mass of the sample was chosen as to minimize the noise-to-signal ratio in the analyser readings and the effects of external mass transfer (reaction kinetics can be limited by external mass transfer when large sample masses are used).

\section{Model Development}

\section{Two-Phase Reactor Model}

Hydrodynamics. A typical method for modelling the hydrodynamics of fluidized-bed reactors is with two-phase theory. ${ }^{22,23}$ Two-phase theory assumes that the fluidized bed can be modelled as two phases: the bubble phase and the particulate phase. The model presented in this paper assumes that all the gas above that needed for minimum fluidization passes through the reactor as bubbles and that the particulate phase retains the minimum fluidization conditions. This means that the particulate phase retains the same voidage seen at minimum fluidization, $\varepsilon_{\mathrm{mf}}$, and that its superficial velocity is equivalent to $U_{\mathrm{mf}}$ 
Table 2 Operating conditions for the experiments/ input conditions for the two-phase model.

\begin{tabular}{llllll}
\hline \hline $\begin{array}{l}\text { Sample Mass }(g) \\
355-425 \mu \mathrm{m}\end{array}$ & $\begin{array}{l}\text { Sand Bed }(g) \\
425-500 \mu \mathrm{m}\end{array}$ & U/Umf & $P($ bara $)$ & $T\left({ }^{\circ} \mathrm{C}\right)$ & $\begin{array}{l}\mathrm{CO}_{2} \text { Concentration } \\
(\text { vol \%) }\end{array}$ \\
\hline \hline 0.5 & 50 & 3 & $1.5-5$ & $550-750$ & $3.75-30$ \\
\hline
\end{tabular}

(the minimum fluidization velocity). Consequently, the bubble phase fluidization velocity can be given by $U-U_{m f} .^{23}$ The model also assumes that gas-solid reactions only take place within the particulate phase.

The work presented in this paper models the particulate phase and a bubble phase as a single CSTR and PFR, respectively (Figure 2). The PFR was discretized into 100 (elements) in series via the finite volumes method so that it was possible to translate the governing material balances into ordinary differential equations (ODEs). The plenum chamber and freeboard were modelled as CSTRs without reaction terms.

Figure 2 shows a schematic diagram of the reactor model. The curved arrows represent mixing within the individual sections of the reactor, gas interchange is represented by double-ended arrows, the outlet gas flows for different components of the reactor are denoted by dashed arrows, and the solid, single-ended arrows represent the total inlet and outlet flow of gas. In this chapter, $y_{\mathrm{CO} 2}$ represents the molar fraction of $\mathrm{CO}_{2}$ in the relevant gas stream/phase. The subscripts $b$ and $p$ refer, respectively, to the bubble phase and particulate phase.

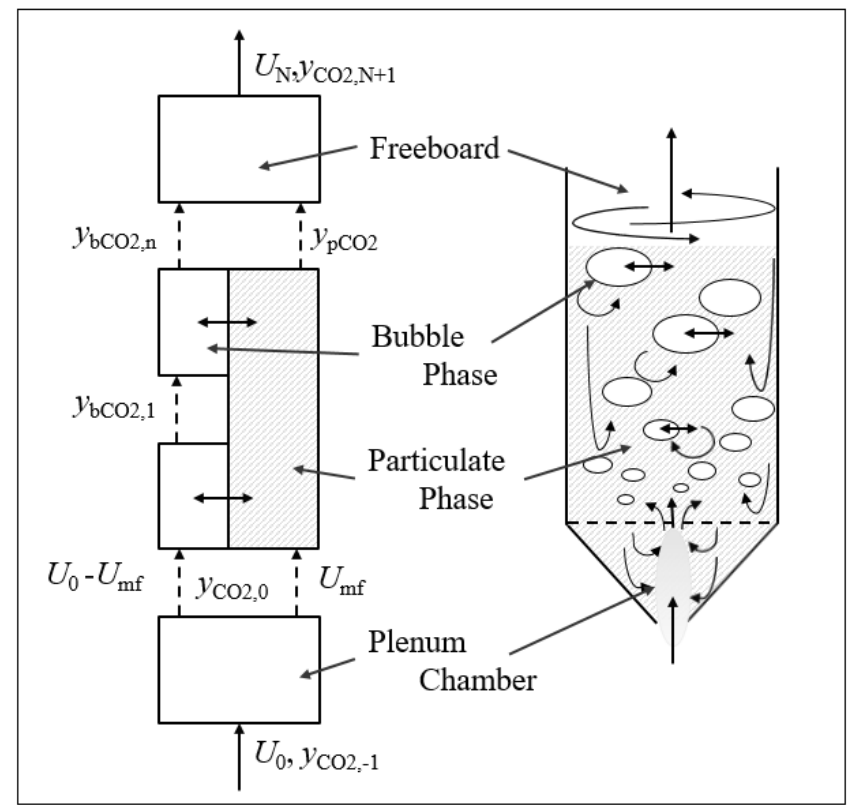

Figure 2 The two-phase reactor model represented as a block diagram

Bubble Size and Velocity. In order to model the gas interchange between the two phases (Figure 3), it was necessary to first determine how the bubble diameter changed within the reactor. To this end, the Mori and Wen ${ }^{24}$ correlation for bubble sizes was utilised to determine the bubble dimensions at different heights:

$$
\frac{d_{\mathrm{bm}}-d_{\mathrm{b}}(z)}{d_{\mathrm{bm}}-d_{\mathrm{b} 0}}=\mathrm{e}^{-0.3 z / d_{\mathrm{R}}}
$$

where $d_{b o}$ is the initial bubble diameter. $d_{\mathrm{bm}}$ represents the maximum bubble diameter which can be achieved in a deep fluidised bed of diameter $d_{\mathrm{R}}$ and $d_{\mathrm{b}}(z)$ is the bubble diameter at height, $z$ within the bed. Eq 1 was reported to be valid over the following ranges for Geldart group B and D powders, with an accuracy of $\pm 50 \%$ :

$$
\begin{gathered}
d_{\mathrm{R}} \leq 1.3 \mathrm{~m} \\
0.005 \leq U_{\mathrm{mf}} \leq 0.2 \mathrm{~m} \mathrm{~s}^{-1} \\
60 \leq d_{\mathrm{p}} \leq 450 \mu \mathrm{m} \\
U-U_{\mathrm{mf}} \leq 0.48 \mathrm{~m} \mathrm{~s}^{-1}
\end{gathered}
$$

Since, the conditions used in this investigation fall within the boundaries of those mentioned above, it was deemed appropriate to use Mori and Wen's correlation to predict the bubble growth behaviour. The initial bubble diameter was taken to be $5.8 \mathrm{~mm}$ : This was the diameter of the entrance orifice of the quartz liner used in the experiments. The maximum bubble diameter, $d_{\mathrm{bm}}$ can be calculated by the following equation:

$$
d_{\mathrm{bm}}=0.65\left(\frac{\pi}{4} d_{\mathrm{R}}^{2}\left(U-U_{\mathrm{mf}}\right)\right)^{0.4} \quad[\mathrm{~cm}]
$$

However, even though the conditions fell within the suggested applicable region reported by the authors, ${ }^{24}$ the value of $d_{\mathrm{bm}}$ at the top of the reactor calculated from the above equation was $30 \%$ greater than the bed diameter, so the maximum bubble size, $d_{\mathrm{bm}}$, was set to be equal to $d_{\mathrm{R}}$ (the maximum size the bubble could physically be in this reactor). This suggests an onset of slug flow at the top of the fluidised bed. With these values for the maximum bubble size and the initial bubble size, it was possible to obtain the bubble size at every height in the reactor model by integrating eq 1 into the reactor model. The bubble through-flow $\left(Q_{\mathrm{b}}\right)$ was then calculated with the knowledge of the bubble diameters using eq 3 and the rate of exchange between the two phases per unit of the bubble volume $\left(Q_{\mathrm{b}} / V_{\mathrm{b}}\right)$ was determined with eq $5:^{25}$

$$
\begin{aligned}
& Q_{\mathrm{b}}=\frac{3}{4} u_{\mathrm{mf}} \pi d_{\mathrm{b}}^{2} \\
& V_{\mathrm{b}}=\frac{1}{6} \pi d_{\mathrm{b}}^{3} \\
& \frac{Q_{\mathrm{b}}(z)}{V_{\mathrm{b}}(z)}=\frac{4.5 u_{\mathrm{mf}}}{\mathrm{d}_{\mathrm{b}}(z)}
\end{aligned}
$$


Bubble and Particulate Phases. From the material flow diagram depicted in Figure 3, it was possible to derive a discretised mole balances for the bubble phase (Eq 6) and particulate phase (Eq 7).

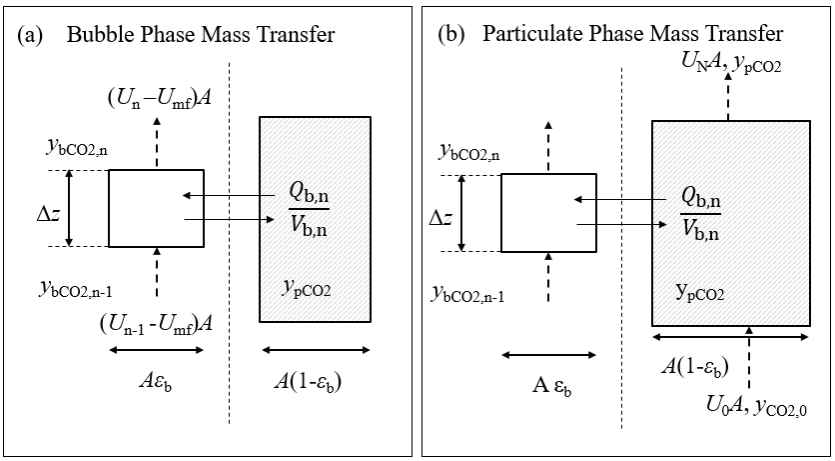

Figure 3 A material flow diagram for a singular increment within the two-phase reactor model for the bubble phase (a) and the particulate phase (b).

Bubble Phase:

$$
\begin{aligned}
& \varepsilon_{\mathrm{b}} A \Delta z \frac{\mathrm{d} y_{\mathrm{bCO}_{2}, \mathrm{n}}}{\mathrm{d} t}=\left(U_{\mathrm{n}-1}-U_{\mathrm{mf}}\right) y_{\mathrm{bCO}_{2}, \mathrm{n}-1} A \\
& -\left(U_{\mathrm{n}}-U_{\mathrm{mf}}\right) y_{\mathrm{bCO}_{2}, \mathrm{n}} A+\frac{Q_{\mathrm{b}, \mathrm{n}} \varepsilon_{\mathrm{b}} A \Delta z}{V_{\mathrm{b}, \mathrm{n}}}\left(y_{\mathrm{pCO}_{2}}-y_{\mathrm{bCO}_{2}, \mathrm{n}}\right) \\
& \frac{\mathrm{d} y_{\mathrm{bCO}_{2}, \mathrm{n}}}{\mathrm{d} t}=-\frac{1}{\varepsilon_{\mathrm{b}}} \frac{\left(U_{\mathrm{n}}-U_{\mathrm{mf}}\right) y_{\mathrm{bCO}_{2}, \mathrm{n}}-\left(U_{\mathrm{n}-1}-U_{\mathrm{mf}}\right) y_{\mathrm{bCO}_{2}, \mathrm{n}-1}}{\Delta z} \\
& +\frac{Q_{\mathrm{b}, \mathrm{n}}}{V_{\mathrm{b}, \mathrm{n}}}\left(y_{\mathrm{pCO}_{2}}-y_{\mathrm{bCO}_{2}, \mathrm{n}}\right)
\end{aligned}
$$

Particulate Phase:

$$
\begin{aligned}
& \varepsilon_{\mathrm{mf}}\left(1-\varepsilon_{\mathrm{b}}\right) A H_{\mathrm{f}} \frac{P}{R T} \frac{\mathrm{d} y_{\mathrm{pCO}_{2}}}{\mathrm{~d} t}=-U_{\mathrm{mf}} A \frac{P}{R T} \Delta y_{\mathrm{pCO}_{2}} \\
& +\sum_{n=1}^{N} \frac{Q_{\mathrm{b}, \mathrm{n}} \varepsilon_{\mathrm{b}} A}{V_{\mathrm{b}, \mathrm{n}}} \frac{P}{R T}\left(y_{\mathrm{bCO}_{2}, \mathrm{n}}-y_{\mathrm{pCO}_{2}}\right) \Delta z+r_{\mathrm{CO}_{2}}\left(1-\varepsilon_{\mathrm{b}}\right) \\
& \frac{\mathrm{d} y_{\mathrm{pCO}_{2}}}{\mathrm{~d} t}=-\frac{U_{\mathrm{mf}}}{\varepsilon_{\mathrm{mf}}\left(1-\varepsilon_{\mathrm{b}}\right)} \frac{y_{\mathrm{pCO}_{2}}-y_{\mathrm{CO}_{2}, 0}}{H_{\mathrm{f}}} \\
& +\frac{1}{\varepsilon_{\mathrm{mf}}\left(1-\varepsilon_{\mathrm{b}}\right)} \sum_{n=1}^{N} \frac{Q_{\mathrm{b}, \mathrm{n}}}{V_{\mathrm{b}, \mathrm{n}}} \frac{\Delta z}{H_{\mathrm{f}}}\left(y_{\mathrm{bCO}_{2}, \mathrm{n}}-y_{\mathrm{pCO}_{2}}\right)+\frac{r_{\mathrm{CO}_{2}}}{\varepsilon_{\mathrm{mf}} A H_{\mathrm{f}}} \frac{R T}{P}
\end{aligned}
$$

Here, the fraction of bubbles in the fluidised bed is denoted as $\varepsilon_{\mathrm{b}}, U_{\mathrm{n}}$ denotes the fluidizing gas velocity, $A$ is the cross-sectional area of the entire bed and $\Delta z$ is the discretised length of an individual PFR element. $H_{\mathrm{f}}$ represents both the fluidised bed height and the accumulative sum of $\Delta z$. The bed voidage at minimum fluidisation, $\varepsilon_{\mathrm{mf}}$ was assumed to be the voidage within the particulate phase. The rate of reaction of $\mathrm{CO}_{2}$ in mol s${ }^{-1}$ is denoted by $r_{\mathrm{CO} 2}$ (the full expression for the reaction term will be discussed in the following section).

To account for the change in number of moles (and the volumetric flow rate of gas) in the system owing to the carbonation reaction, it was necessary to derive an expression for the fluidizing gas velocity as a function of the $\mathrm{CO}_{2}$ concentration in the particulate phase. To this end, an inert $\mathrm{N}_{2}$ mole balance was written for each discretised element within the reactor to determine the variation in the fluidizing gas velocity over the length of the reactor.

$$
\begin{aligned}
& n_{\mathrm{N}_{2}, \mathrm{n}-1} y_{\mathrm{N}_{2}, \mathrm{n}-1}=n_{\mathrm{N}_{2}, \mathrm{n}} y_{\mathrm{N}_{2}, \mathrm{n}} \\
& n_{\mathrm{N}_{2}, \mathrm{n}-1}\left(1-y_{\mathrm{bCO}_{2}, \mathrm{n}-1}\right)=n_{\mathrm{N}_{2}, \mathrm{n}}\left(1-y_{\mathrm{bCO}_{2}, \mathrm{n}}\right)
\end{aligned}
$$

By converting the molar flow rate into the gas velocity using the ideal gas law, the $\mathrm{N}_{2}$ balance can be reduced to $\mathrm{Eq}$ 9.

$$
\frac{P A U_{\mathrm{n}-1}}{R T}\left(1-y_{\mathrm{bCO}_{2}, \mathrm{n}-1}\right)=\frac{P A U_{\mathrm{n}}}{R T}\left(1-y_{\mathrm{bCO}_{2}, \mathrm{n}}\right)
$$

Hence:

$$
U_{\mathrm{n}}=U_{\mathrm{n}-1} \frac{\left(1-y_{\mathrm{bCO}_{2}, \mathrm{n}-1}\right)}{\left(1-y_{\mathrm{bCO}_{2}, \mathrm{n}}\right)}
$$

Plenum Chamber and Freeboard. Figures $4 \mathrm{a}$ and $4 \mathrm{~b}$ depict the mixing process within the plenum chamber and the freeboard of the reactor. The mole balances are given by Eq 10 and 11 , respectively.

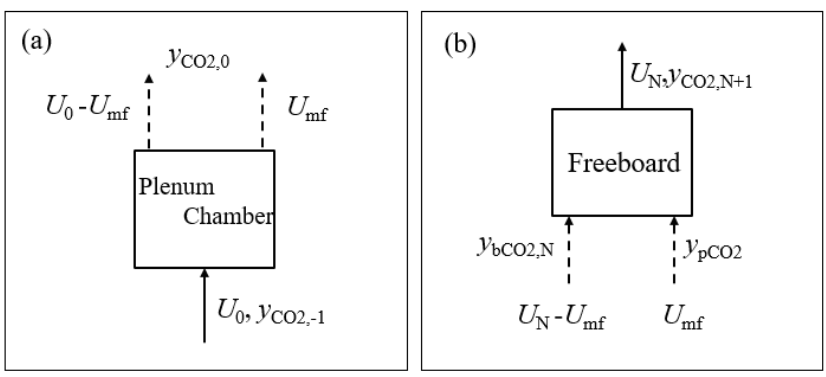

Figure 4 A material flow diagram for the plenum chamber (4a) and the freeboard (4b).

Plenum chamber mole balance:

$$
\begin{aligned}
& \frac{P V_{\mathrm{pl}}}{R T} \frac{\mathrm{d} y_{\mathrm{CO}_{2} 0}}{\mathrm{~d} t}= \\
& U_{0} A \frac{P}{R T} y_{\mathrm{CO}_{2},-1}-\left(U_{0}-U_{\mathrm{mf}}\right) A \frac{P}{R T} y_{\mathrm{CO}_{2}, 0}-U_{\mathrm{mf}} A \frac{P}{R T} y_{\mathrm{CO}_{2}, 0} \\
& U_{0} A \tau_{\mathrm{pl}} \frac{\mathrm{d} y_{\mathrm{CO}_{2} 0}}{\mathrm{~d} t} \\
& =U_{0} A y_{\mathrm{CO}_{2},-1}-\left(U_{0}-U_{\mathrm{mf}}\right) A y_{\mathrm{CO}_{2}, 0}-U_{\mathrm{mf}} A y_{\mathrm{CO}_{2}, 0} \\
& \tau_{\mathrm{pl}} \frac{\mathrm{d} y_{\mathrm{CO}_{2} 0}}{\mathrm{~d} t}=y_{\mathrm{CO}_{2},-1}-y_{\mathrm{CO}_{2}, 0}
\end{aligned}
$$

Freeboard mole balance:

$$
\begin{aligned}
& \frac{P V_{\mathrm{fb}}}{R T} \frac{\mathrm{d} y_{\mathrm{CO}_{2}, \mathrm{~N}+1}}{\mathrm{~d} t}=U_{\mathrm{mf}} A \frac{P}{R T} y_{\mathrm{p}_{\mathrm{CO} 2}} \\
& +\left(U_{\mathrm{N}}-U_{\mathrm{mf}}\right) A \frac{P}{R T} y_{\mathrm{b}, \mathrm{CO}_{2} \mathrm{~N}}-U_{\mathrm{N}} A \frac{P}{R T} y_{\mathrm{CO}_{2}, \mathrm{~N}+1} \\
& U_{\mathrm{N}} A \tau_{\mathrm{fb}} \frac{\mathrm{d} y_{\mathrm{CO}_{2}, \mathrm{~N}+1}}{\mathrm{~d} t}=U_{\mathrm{mf}} A y_{\mathrm{p}_{\mathrm{CO} 2}} \\
& +\left(U_{\mathrm{N}}-U_{\mathrm{mf}}\right) A y_{\mathrm{b}, \mathrm{CO}_{2} \mathrm{~N}}-U_{\mathrm{N}} A y_{\mathrm{CO}_{2}, \mathrm{~N}+1}
\end{aligned}
$$




$$
\begin{aligned}
& \tau_{\mathrm{fb}} \frac{\mathrm{d} y_{\mathrm{CO}_{2}, \mathrm{~N}+1}}{\mathrm{~d} t} \\
& =y_{\mathrm{p}_{\mathrm{CO} 2}}\left(\frac{U_{\mathrm{mf}}}{U_{\mathrm{N}}}\right)+y_{\mathrm{b}, \mathrm{CO}_{2} \mathrm{~N}}\left(\frac{U_{\mathrm{N}}-U_{\mathrm{mf}}}{U_{\mathrm{N}}}\right)-y_{\mathrm{CO}_{2}, \mathrm{~N}+1}
\end{aligned}
$$

In the series of equations above, the mole fraction of gas is denoted as $y$, and $\tau$ represents the mixing time constants. The volume of the plenum chamber and freeboard are denoted as $V_{\mathrm{pl}}$ and $V_{\mathrm{fb}}$, respectively.

The parameters for the model were chosen based on experimentally measured quantities. The unfluidized bed height was measured as $7 \mathrm{~mm}$ and the fluidised bed height was calculated to be $11 \mathrm{~mm}$ using eqs SI1-5 (see Supporting Information). The voidage at incipient fluidisation, $\varepsilon_{\mathrm{mf}}$ was approximated as 0.42 based on literature values for a bed of spherical particles. ${ }^{26}$ The mixing time in the plenum chamber, $\tau_{\mathrm{pl}}$ was set to $0.1 \mathrm{~s}$ (the mixing of the gas prior to the reaction was rapid). The value for the freeboard mixing time constant was chosen to be $3.5 \mathrm{~s}$ (equivalent to the measured response time of the entire reactor sampling system including the gas analyser, $\tau_{\text {mix }}$ ).

Reaction Rate Modelling. In this work, the random pore model, which was developed by Bhatia and Perlmutter ${ }^{1}$ was used to describe the interaction between $\mathrm{CaO}$ and $\mathrm{CO}_{2}$ in the particulate phase. A few assumptions were made. Firstly, it was assumed that there were no external mass transfer limitations. This was a fair assumption as the product of the external mass transfer and the particle surface area was an order of magnitude greater than the product of the observed rate constant and the particle volume. Therefore, the particle surface concentration can be assumed to be equal to the bulk phase concentration. Furthermore, the intraparticle mass transfer resistance was assumed to be negligible so that there were no concentration gradients across the particle.

The carbonation reaction is known to have an initial kinetically-controlled step followed by a diffusion-controlled step, so two forms of the random pore model have been used in this work to reflect this. Technically a single reaction equation should be used to describe the whole carbonation process as opposed to separating it into two distinct parts. However, previous investigators who have used the random pore model to characterise the carbonation reaction have demonstrated the existence of a sudden transition from the kinetic-controlled regime to the diffusioncontrolled stage. ${ }^{1,10}$ Grasa et al. ${ }^{10}$ suggested that, based on these observations, it was more practical to split the model into two parts: the random pore model with and without the effects of product layer diffusion. They argued that substantially lower conversions relative to experimental results would be obtained if the effects of product layer diffusion were incorporated throughout the entire reaction.

For the kinetically-controlled phase, the reduced form of the random pore model (eq 12) was utilised. Here, the product layer diffusion resistance is assumed to be negligible.

$$
r=\frac{\mathrm{d} X}{\mathrm{~d} t}=\frac{k_{\mathrm{S}} S_{0}\left(C_{\mathrm{CO}_{2}}-C_{\mathrm{CO}_{2} \mathrm{eq}}\right)(1-X) \sqrt{1-\psi \ln (1-X)}}{\left(1-\varepsilon_{0}\right)}
$$

$k_{\mathrm{s}}$ is the surface reaction rate constant, $S_{0}$ is the initial surface area per volume of the sorbent particle, and $C_{\mathrm{CO} 2}$ and
$C_{\mathrm{co2} \text {,eq }}$ denote the $\mathrm{CO}_{2}$ concentration in the bulk phase and at the carbonation/calcination equilibrium, respectively. The conversion is represented by $X, \varepsilon_{0}$ is the initial porosity of the particle and the structure parameter (see below) is denoted as $\psi$.

For the diffusion-controlled step, the complete random pore model was used (eq 13). The transition from the kinetically-controlled step to the slower diffusion-controlled step can be marked by a drop in the observed reaction rate owed to the formation of a product layer which has reached a critical thickness. ${ }^{27}$ After the rate of reaction has peaked, the effect of the product layer resistance becomes more pronounced and takes over the reaction rate. To account for this effect, the inclusion of the modified Biot modulus, $\beta$ which incorporates the product layer diffusivity was necessary. The greater the magnitude of the modified Biot modulus, the more the reaction is limited by the product diffusion effects.

$$
r=\frac{\mathrm{d} X}{\mathrm{~d} t}=\frac{k_{\mathrm{S}} S_{0}\left(C_{\mathrm{CO}_{2}}-C_{\mathrm{CO}_{2} \mathrm{eq}}\right)(1-X) \sqrt{1-\psi \ln (1-X)}}{\left(1-\varepsilon_{0}\right)\left(1+\frac{\beta Z}{\psi}(\sqrt{1-\psi \ln (1-X)}-1)\right)}
$$

Where:

$$
\begin{aligned}
& \psi=\frac{4 \pi L_{0}\left(1-\varepsilon_{0}\right)}{S_{0}} \\
& \beta=\frac{2 k_{S}\left(1-\varepsilon_{0}\right)}{M_{\mathrm{CaO}_{0} S_{0} D_{\mathrm{p}}}} \\
& Z=\frac{\rho_{\mathrm{CaO}} M_{\mathrm{CaCO}_{3}}}{\rho_{\mathrm{CaCO}_{3} M_{\mathrm{CaO}}}}
\end{aligned}
$$

Here, $r$ is the rate of reaction in $\mathrm{s}^{-1}$ and $X$ is the conversion. $\psi$ (the structure parameter) describes the internal pore structure of $\mathrm{CaO}$ and was calculated from first-hand Mercury Intrusion Porosimetry data of $\mathrm{CaO}$ via the use of the following equations: ${ }^{28}$

$$
\begin{aligned}
V_{\mathrm{p}} & =\int v_{\mathrm{o}}(r) \mathrm{d} r \\
\varepsilon_{0} & =\frac{V_{\mathrm{p}}}{V_{\mathrm{p}}+\frac{1}{\rho_{\mathrm{CaO}}}} \\
L_{0} & =\frac{1}{\pi V_{\mathrm{p}}} \int \frac{v_{\mathrm{o}}(r)}{r^{2}} \mathrm{~d} r
\end{aligned}
$$

Here, $v_{0}(r)$ is the pore size distribution function obtained from BET data. The total pore volume, initial porosity and length of the pore system per unit volume are denoted as $V_{\mathrm{p}}, \varepsilon_{0}$, and $L_{0}$ respectively.

$$
S_{0}=\frac{S_{\mathrm{g}}}{\rho_{\text {envelope }}}
$$

$S_{0}$, which is the surface area per unit volume was taken from a combination of BET surface area data and helium adsorption density data. The envelope density of $\mathrm{CaO}$ is given by $\rho_{\text {envelope. }}$ Table 3 displays the values of these parameters for freshly calcined Longcliffe limestone.

Table 3 Random Pore Model parameters for calcined Longcliffe limestone.

\begin{tabular}{ccccc}
\hline \hline $\begin{array}{c}S_{0} \\
\left(\mathrm{~m}^{2} \mathrm{~m}^{-3}\right)\end{array}$ & $\begin{array}{c}L_{0} \\
\left(\mathrm{~m} \mathrm{~m}^{-3}\right)\end{array}$ & $\varepsilon_{0}$ & $\psi$ & $Z$ \\
\hline \hline & & & & \\
$3.06 \times 10^{7}$ & $2.33 \times 10^{14}$ & 0.5 & 1.61 & 2.16 \\
\hline
\end{tabular}


Clearly, there are two unknowns in the rate equation expressions, $k_{\mathrm{s}}$ and $D_{\mathrm{p}}$. In order to solve for these values, the model was fitted to experimental data. Eqs 12 and 13 were substituted into the particulate phase mole balance (eq 2) to complete the reactor model. By minimizing the residual sum of squares (RSS) between the experimental data and model output, it was possible to derive estimations for the two unknowns (fitting parameters) at a range of operating conditions.

\section{RESULTS AND DISCUSSION}

Deconvolution of Data. Figure 5 shows the change in $\mathrm{CO}_{2}$ concentration during carbonation recorded by the IR gas analyser. To determine the intrinsic rate kinetics of carbonation, the gas concentration was firstly deconvoluted using a published method by Fennell et al. ${ }^{29}$ The method assumed that the sampling system, and the fluidised bed behaved like CSTRs in series with negligible second order mixing effects. Based on these assumption, the true gas concentration in the reactor, $C_{\mathrm{t}}$ can be calculated with eq 18 .

$$
C_{\mathrm{t}}=C_{\mathrm{m}}+\tau_{\text {mix }} \frac{\mathrm{d} C_{\mathrm{m}}}{\mathrm{d} t}
$$

Here, the measured (convoluted) gas concentration is denoted as $C_{\mathrm{m}}$ and the overall mixing (response) time in the system (combined mixing time of the reactor and sampling system) is given by $\tau_{\text {mix. }}$. The overall mixing time was found to be approximately $3.5 \mathrm{~s}$. The deconvoluted gas concentration is superimposed on the measured gas concentration (Figure 5).

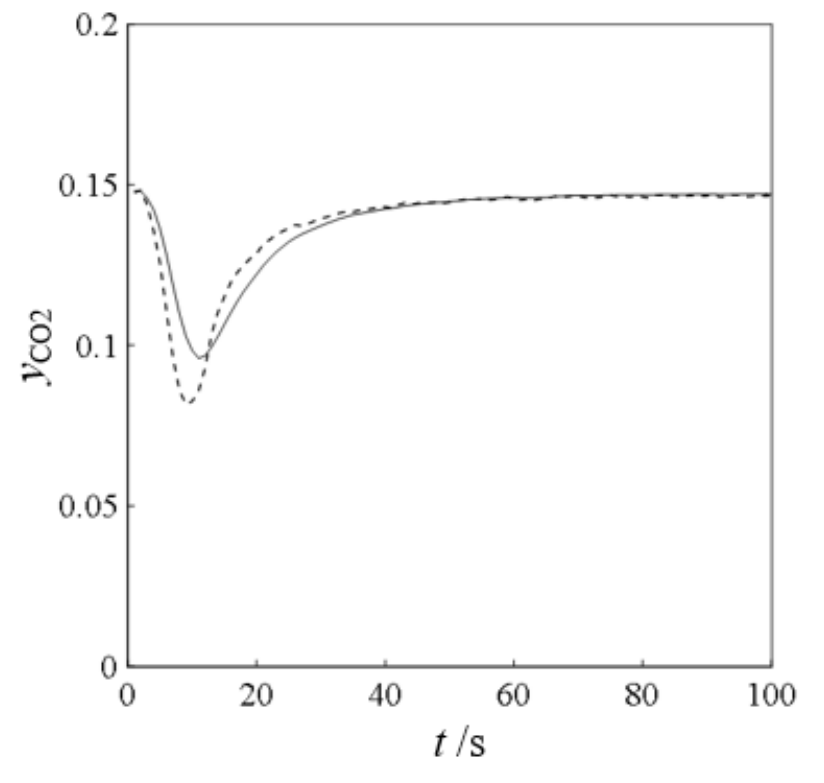

- Convoluted concentration profile - - -Deconvoluted concentration profile

Figure 5 Deconvoluted analyser signal for carbonation experiments of Longcliffe-derived $\mathrm{CaO}(0.5 \mathrm{~g}, 355-425 \mu \mathrm{m})$ in the PFBR with fluidizing gas of $15 \mathrm{vol} \% \mathrm{CO}_{2}$ balanced in $\mathrm{N}_{2}$, temperature $=650{ }^{\circ} \mathrm{C}$, pressure $=1.5$ bara, $U / U_{\mathrm{mf}}=3\left(55 \mathrm{ml} \mathrm{s}^{-1}\right.$ @SATP).
From the deconvoluted data, the reaction rate can be calculated by eq 19 where $n_{\mathrm{co}}$ Carbonation represents the rate of $\mathrm{CO}_{2}$ uptakes in mol s${ }^{-1}$ and $w_{\mathrm{CaO}}$ is the mass of $\mathrm{CaO}$ injected into the reactor.

$$
r=\frac{n_{\mathrm{CO}_{2} \text { Carbonation }}}{w_{\mathrm{CaO}}}
$$

The $\mathrm{CaO}$ conversion/carrying capacity (after $100 \mathrm{~s}$ ) in terms of $\mathrm{mol} \mathrm{CO}_{2}$ captured/mol $\mathrm{CaO}$ injected was computed using Eq 20.

$$
X=\frac{M_{\mathrm{CaO}}}{w_{\mathrm{CaO}}} \int_{t=0}^{t=100} n_{\mathrm{CO}_{2} \text { Carbonation }} \mathrm{d} t
$$

In order to make the reaction behaviour in the reactor consistent with the assumptions made for the random pore model (negligible external mass transfer resistances and intraparticle diffusion resistances) small sample masses and small particle sizes were used. Figures $6 \mathrm{a}$ and $6 \mathrm{~b}$ show the reaction rate (normalised for the sample mass) plotted against time for different sample masses and particle sizes, respectively. Figure 6a shows negligible differences (within experimental error) between the reaction profiles for masses ranging from 0.1 to $0.5 \mathrm{~g}$ which means there were no external mass diffusion limitations for sample weighing less than $0.5 \mathrm{~g}$. Figure $6 \mathrm{~b}$ suggests that the level of intraparticle diffusion resistance is at a minimum for particle with diameters smaller than $500 \mu \mathrm{m}$. Consequently, the sample mass and particle size fraction were chosen to be $0.5 \mathrm{~g}$ and $355-425 \mu \mathrm{m}$. Smaller sample masses and particle sizes were neglected due to higher noise-to-signal ratios and greater susceptibility to attrition and elutriation. In order to justify the assumption of low intraparticle diffusion resistances for the diffusion-controlled step for our chosen size range, the effectiveness factors as a function of conversion for our experiments were calculated using eqs 19-26 assuming an estimate of 2 for the tortuosity factor, $\tau$. The change in porosity, $\varepsilon$ as the product layer develops (and therefore change in conversion, $X$ ) was calculated using a volume balance (eqs 24-26). It can be seen that the effectiveness factor remains quite high throughout the entire reaction process (Figure 7).

$$
\eta(X)=\frac{3}{\phi(X)^{2}}(\phi(X) \operatorname{coth} \phi(X)-1)
$$

Where:

$$
\begin{aligned}
& \phi(X)=r_{\mathrm{P}} \sqrt{\frac{k_{\mathrm{i}}(X)}{D_{\text {eff }}(X)}} \\
& D_{\text {eff }}(X)=\frac{\varepsilon(X)}{\tau}\left(\frac{1}{D_{\mathrm{K}, \text { eff }}(\mathrm{X})}+\frac{1}{D_{A B, \text { eff }}(\mathrm{X})}\right)^{-1} \\
& D_{\mathrm{AB}}(X)=1.8583 \times 10^{-7} \sqrt{T^{3}\left(\frac{1}{M_{\mathrm{A}}}+\frac{1}{M_{\mathrm{B}}}\right)} \frac{1}{P \sigma_{\mathrm{AB}}^{2} \Omega_{\mathrm{AB}}^{(1,1) *}} \\
& D_{\mathrm{K}}(X)=194 \frac{\varepsilon(X)}{S_{0}(1-X) \rho_{\text {envelope, } \mathrm{CaO}}(X)} \sqrt{\frac{T}{M_{\mathrm{CaO}}}} \\
& \varepsilon(X)=\frac{V_{\mathrm{p}}(X)}{V_{\mathrm{sample}}(X)} \\
& V_{\mathrm{p}}(X)=V_{\mathrm{p} 0}-\Delta V_{\mathrm{p}}(X) \\
& \Delta V_{\mathrm{p}}(X)=V_{\mathrm{CaCO}_{3}, \text { formed }}(X)-V_{\mathrm{CaO}, \text { reacted }}(X)
\end{aligned}
$$



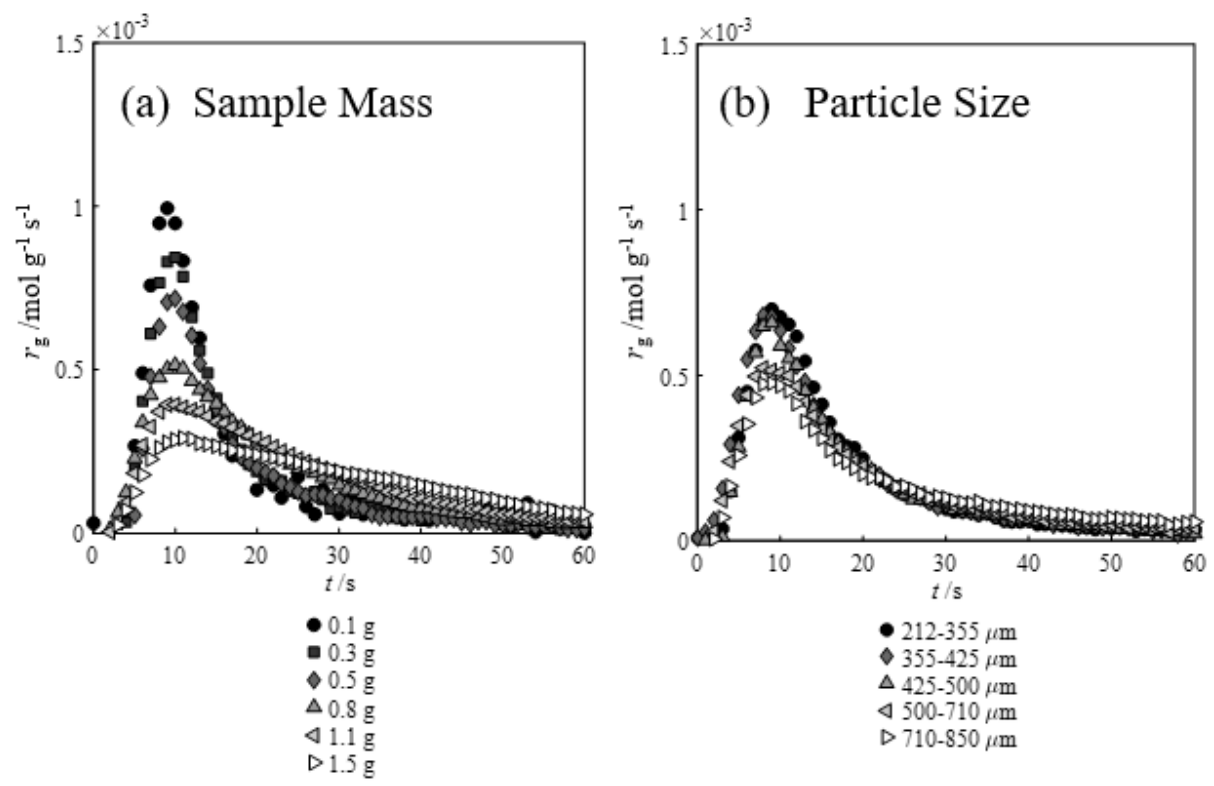

Figure 6 Rate (normalised for mass) vs time for different sample masses (a) and different particle sizes (b) of $\mathrm{CaO}$ for carbonation experiments of Longcliffe-derived $\mathrm{CaO}(0.5 \mathrm{~g}, 355-425 \mu \mathrm{m})$ in the PFBR with fluidizing gas of 15 vol\% $\mathrm{CO}_{2}$, balanced in $\mathrm{N}_{2}$, temperature $=650{ }^{\circ} \mathrm{C}$, pressure $=1.5$ bara, $U / U_{\mathrm{mf}}=3$ (55 $\mathrm{ml} \mathrm{s}^{-1} @$ SATP).

Here, $\eta$ represents the effectiveness factor (the ratio of the observed rate of reaction to the intrinsic rate). It is cal-

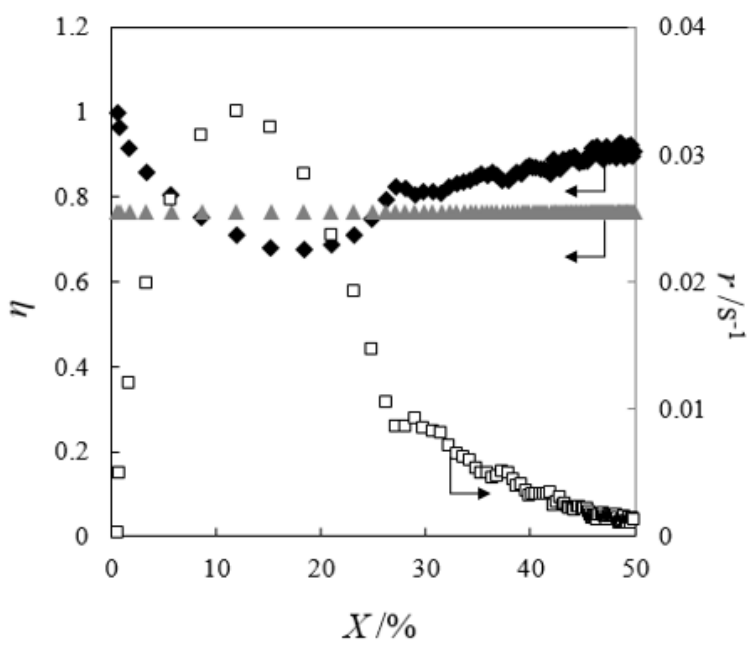

- Effectiveness factor

$\Delta$ Effectivess factor (constant porosity)

$\square$ Reaction rate

Figure 7 Calculated effectiveness factor (assuming changing and non-changing porosity) and rates of reaction against conversion for carbonation of Longcliffe-derived $\mathrm{CaO}(0.5 \mathrm{~g}, 355-$ $425 \mu \mathrm{m})$ in the PFBR with fluidizing gas of $15 \mathrm{vol} \% \mathrm{CO}_{2}$ balanced in $\mathrm{N}_{2}$, temperature $=650{ }^{\circ} \mathrm{C}$, pressure $=1.5$ bara, $U / U_{\mathrm{mf}}=3$ (55 ml s-1 @SATP). culated from a Thiele modulus, denoted $\phi$, which is a function of the particle radius, $r_{\mathrm{p}}$, the first order pseudo-intrinsic rate constant, $k_{\mathrm{i}}$ and the effective diffusivity through the particle, $D_{\text {eff. }}{ }^{12} D_{\mathrm{AB}}$ and $D_{\mathrm{k}}$ represent bulk and Knudsen diffusivity. ${ }^{30,31}$ The bulk diffusion equation for diffusion of a single gaseous component in a dilute binary system was taken from the Chapman-Enskog kinetic theory. ${ }^{30}$ It is a function of the molecular weights of the participating gases, the Lennard-Jones $(12,6)$ parameters, $\varepsilon_{\mathrm{AB}}$ and $\sigma_{\mathrm{AB}}$, and the dimensionless quantity, the collision integral $\left(\Omega_{\mathrm{AB}}^{(1,1) *}\right)$. The collision integrals were obtained from work by Klein and Smith $^{32} . S_{0}, \varepsilon_{0}$ and $V_{\mathrm{p} 0}$ were calculated with eqs 14,15 and 17. Figure 7 also demonstrates that the effectiveness factor was similar for data analysis assuming no change in porosity owed to product layer formation and a change in porosity. The calculated effectiveness factor assuming there was no change in porosity was used during the rate analysis of the experimental work.

Obtaining Rate Constants and Product Layer Diffusivity. The built-in ordinary differential equation solver, ode15s in MATLAB, was used to evaluate the system of equations highlighted in the previous sections to obtain the reaction kinetics of carbonation for the conditions given in Table 2. The concentration profiles obtained from the experiments here were taken straight from the gas analyser output without correcting for response time effects (convoluted data). The convoluted data was used here as opposed to deconvoluted data as the reactor model incorporated the deconvolution effects through the sampling and freeboard mixing time constant.

The fitting parameters were obtained in two steps. In the first step, only the reduced form of the random pore model, 


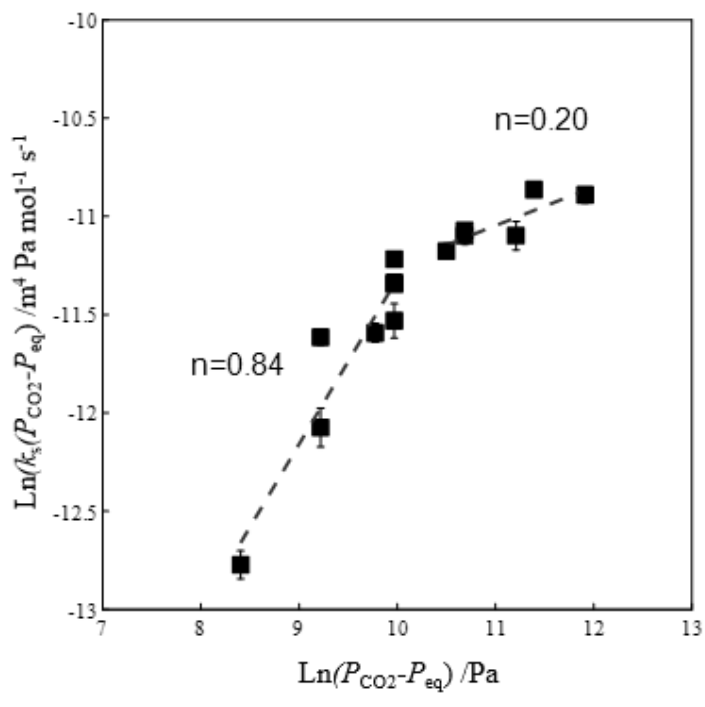

Carbonation rate dependence on driving force at $650^{\circ} \mathrm{C}$

Figure 9 Plot of the initial surface rate constants versus the $\mathrm{CO}_{2}$ driving force.

eq 12 was implemented into the reactor model. This reduced the fitting parameters to just one, the surface reaction rate constant, $k_{s}$. To determine an initial guess for this parameter, $k_{s}$ was fitted by minimizing the RSS between the model output and the experimental result for the kinetically-controlled part of the carbonation reaction.

Figure 8 shows a plot of estimated values for the surface rate constants plotted against the $\mathrm{CO}_{2}$ driving force (inlet $\mathrm{CO}_{2}$ partial pressure, $P_{\mathrm{CO} 2}$ minus the equilibrium partial pressure, $\left.P_{\mathrm{Coz} e q}\right)$. It can be seen in this figure that the order of reaction appears to change from first to approximately zero order above a certain value of $P_{\mathrm{CO} 2}$. This change in order of reaction falls in line with observations by other researchers. 1 , 9, 10,33 The partial pressure at which the transition occurs, denoted $P_{\mathrm{CO} 2 \text {, max }}$ in this paper was estimated through a series of steps. Firstly, an initial guess for the transition partial pressure was made by identifying the partial pressure at which the initial rate constant, $k_{\mathrm{s}}$ experienced the greatest change $\left(37.5 \mathrm{kPa}\right.$ at $\left.650^{\circ} \mathrm{C}\right)$. This initial

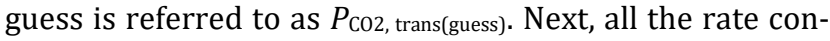
stants that were obtained for conditions where $P_{\mathrm{CO} 2}<P_{\mathrm{CO} 2}$, trans(guess) were averaged to obtain a new (averaged) value for the rate constant, denoted as $k_{\mathrm{s} 0}$. Consequently, when $P_{\mathrm{CO} 2}$ falls below the transition partial pressure, eq 29 can be used instead of eq 12 to describe the rate of carbonation in the kinetically-controlled regime.

$$
r=\frac{k_{\mathrm{s} 0} S_{0}\left(P_{\mathrm{CO}_{2}}-P_{\mathrm{CO}_{2} \mathrm{eq}}\right)(1-X) \sqrt{1-\psi \ln (1-X)}}{R T\left(1-\varepsilon_{0}\right)}
$$

In contrast, for the cases where $P_{\mathrm{CO} 2}>P_{\mathrm{CO} 2 \text {, trans(guess) (when }}$ the reaction becomes zero order with respect to $P_{\mathrm{CO} 2}$ ) the rate equation becomes eq 30 since an increase in $P_{\mathrm{CO} 2}$ no longer has any effect on the rate of reaction. In other words, the driving force of the reaction becomes fixed as the difference between the transition partial pressure and the equilibrium partial pressure $\left(P_{\mathrm{CO} 2 \text {, trans }}-P_{\mathrm{CO} 2 \mathrm{eq}}\right)$.

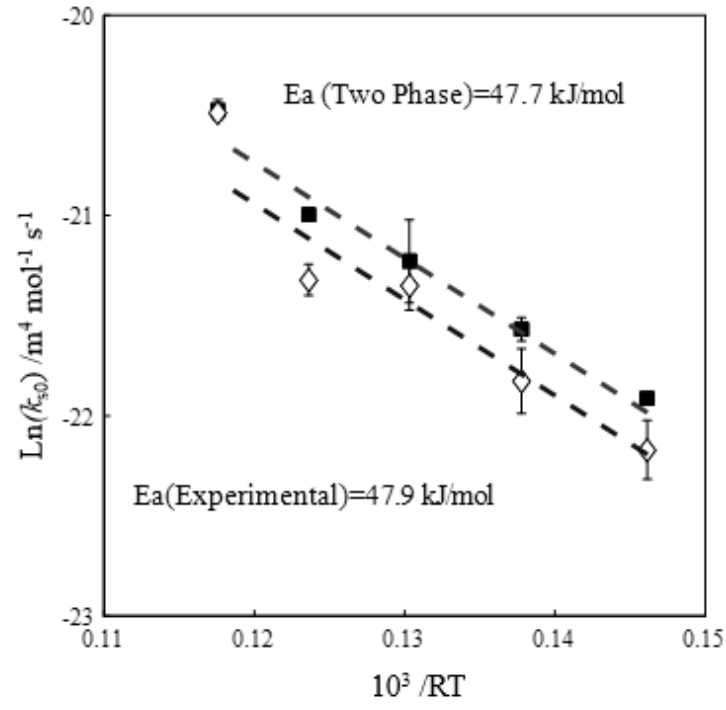

Two Phase model estimate of rate constant activation energy $\checkmark$ Experimental estimate of rate constant activation energy

Figure 8 Arrhenius plot (two-phase model vs CSTR modelled (experimental)) for the surface rate constants in the kineticallycontrolled regime (i.e. when $P_{\mathrm{CO} 2}<P_{\mathrm{CO} 2 \text {, } \max }$ ) for carbonation Longcliffe-derived $\mathrm{CaO}(0.5 \mathrm{~g})$ in the PFBR with fluidizing gas of 15 vol\% $\mathrm{CO}_{2}$ balanced in $\mathrm{N}_{2}$, temperature $=550-750{ }^{\circ} \mathrm{C}$, pressure=1.5 bara, $U / U_{\mathrm{mf}}=3$ (47-67 $\left.\mathrm{ml} \mathrm{s}^{-1} @ \mathrm{SATP}\right)$.

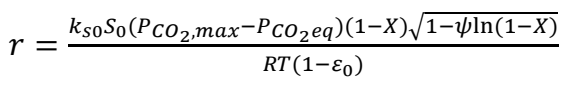

Eq 30 was then equated to eq 12 for the cases where $P_{\mathrm{CO} 2}$

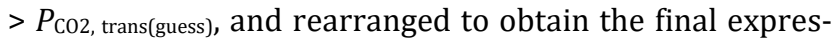
sion for the transition partial pressure (eq 31). Here $k_{\text {s }}$ and $P_{\mathrm{CO} 2}$ were the initial values of the surface rate constant and inlet $\mathrm{CO}_{2}$ partial pressure shown in Figure 8.

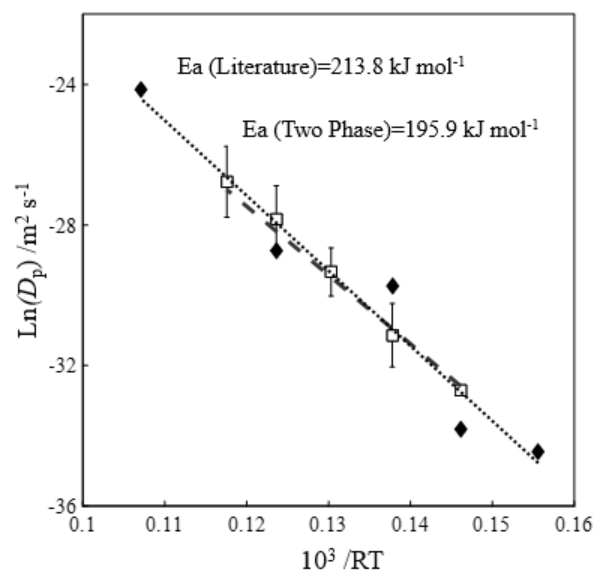

$\square$ Two Phase model estimate of diffusivity activation energy for Longcliffe limestone

- Literature reported diffusivity activation energy for Straussburg limestone

Figure 10 Arrhenius plot (two-phase model vs literature values) for averaged product layer diffusivities for carbonation for of Longcliffe-derived $\mathrm{CaO}(0.5 \mathrm{~g})$ in the PFBR with fluidizing gas of $15 \mathrm{vol} \% \mathrm{CO}_{2}$ balanced in $\mathrm{N}_{2}$, temperature $=550-750{ }^{\circ} \mathrm{C}$, pressure=1.5 bara, $U / U_{\mathrm{mf}}=3$ (47-67 $\left.\mathrm{ml} \mathrm{s}^{-1} @ \mathrm{SATP}\right)$. 


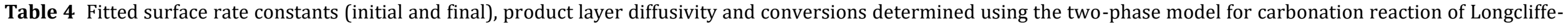
derived $\mathrm{CaO}(0.5 \mathrm{~g}, 255-425 \mu \mathrm{m})$ in 3.75-30 vol\% $\mathrm{CO}_{2}$ balanced in $\mathrm{N}_{2}$, temperature $=550-750{ }^{\circ} \mathrm{C}$, pressure $=1.5-5 \mathrm{bara}, U / U_{\mathrm{mf}}=3\left(47-67 \mathrm{ml} \mathrm{s}{ }^{-1} @ \mathrm{SATP}\right)$.

\begin{tabular}{|c|c|c|c|c|c|c|c|c|c|}
\hline $\begin{array}{l}\text { Temperature } \\
\left({ }^{\circ} \mathrm{C}\right)\end{array}$ & $\begin{array}{l}\text { Pressure } \\
\text { (bara) }\end{array}$ & $\begin{array}{l}\text { Inlet } \mathrm{CO}_{2} \text { Par- } \\
\text { tial Pressure } \\
(\mathrm{kPa})\end{array}$ & $\begin{array}{l}k_{\mathrm{s}} / 10^{-10} \\
\left(\mathrm{~m}^{4} \mathrm{~mol}^{-1} \mathrm{~s}^{-1}\right)\end{array}$ & $\begin{array}{l}k_{\mathrm{s} 0} / 10^{-10} \\
\left(\mathrm{~m}^{4} \mathrm{~mol}^{-1} \mathrm{~s}^{-1}\right)\end{array}$ & $\begin{array}{l}D_{\mathrm{p}} / 10^{-13} \\
\left(m^{2} s^{-1}\right)\end{array}$ & $\begin{array}{l}D_{\mathrm{p} 0} / 10^{-13} \\
\left(m^{2} s^{-1}\right)\end{array}$ & $\begin{array}{l}\text { Transition } P_{\mathrm{C} 02} \\
(\mathrm{kPa})\end{array}$ & $\begin{array}{l}\text { Model Predicted } \\
\text { Conversion (\%) }\end{array}$ & $\begin{array}{l}\text { Experimentally } \mathrm{Ob} \text { - } \\
\text { tained Conversion } \\
(\%)\end{array}$ \\
\hline 550 & 1.5 & 22.5 & 3.05 & 3.05 & 0.09 & 0.06 & 18.9 & 31 & 24 \\
\hline 550 & 3 & 45 & 1.30 & 3.05 & 0.1 & 0.06 & & 31 & 17 \\
\hline 550 & 5 & 75 & 0.75 & 3.05 & 0 & 0.06 & & 29 & 26 \\
\hline 600 & 1.5 & 22.5 & 4.30 & 4.3 & 0.2 & 0.30 & 23.0 & 48 & 42 \\
\hline 600 & 5 & 75 & 1.20 & 4.3 & 0.1 & 0.30 & & 49 & 36 \\
\hline 650 & 1.5 & 5.625 & 6.35 & 6.03 & 2.6 & 1.81 & 28.1 & 36 & 37 \\
\hline 650 & 1.5 & 11.25 & 8.95 & 6.03 & 1.2 & 1.81 & & 54 & 40 \\
\hline 650 & 3 & 11.25 & 5.65 & 6.03 & 2.7 & 1.81 & & 53 & 57 \\
\hline 650 & 5 & 18.75 & 5.25 & 6.03 & 2.6 & 1.81 & & 61 & 60 \\
\hline 650 & 1.5 & 22.5 & 6.30 & 6.03 & 1.3 & 1.81 & & 65 & 52 \\
\hline 650 & 2 & 22.5 & 4.60 & 6.03 & 2.8 & 1.81 & & 65 & 56 \\
\hline 650 & 5 & 22.5 & 5.55 & 6.03 & 1.5 & 1.81 & & 63 & 52 \\
\hline 650 & 5 & 37.5 & 3.85 & 6.03 & 3.1 & 1.81 & & 66 & 62 \\
\hline 650 & 1.5 & 45 & 3.55 & 6.03 & 0.3 & 1.81 & & 70 & 56 \\
\hline 650 & 3 & 45 & 3.45 & 6.03 & 1.3 & 1.81 & & 67 & 55 \\
\hline 650 & 5 & 75 & 2.05 & 6.03 & 0.8 & 1.81 & & 67 & 48 \\
\hline 650 & 3 & 90 & 2.15 & 6.03 & 1.5 & 1.81 & & 69 & 50 \\
\hline 650 & 5 & 150 & 1.25 & 6.03 & 0 & 1.81 & & 69 & 54 \\
\hline 700 & 1.5 & 22.5 & 7.60 & 7.60 & 8.2 & 8.13 & 31.6 & 69 & 65 \\
\hline 700 & 3 & 45 & 5.10 & 7.60 & 14 & 8.13 & & 69 & 69 \\
\hline 700 & 5 & 75 & 3.00 & 7.60 & 2.2 & 8.13 & & 69 & 50 \\
\hline 750 & 1.5 & 22.5 & 12.85 & 12.85 & 5.9 & 23.6 & 29.3 & 70 & 70 \\
\hline 750 & 3 & 45 & 6.00 & 12.85 & 22 & 23.6 & & 70 & 68 \\
\hline
\end{tabular}




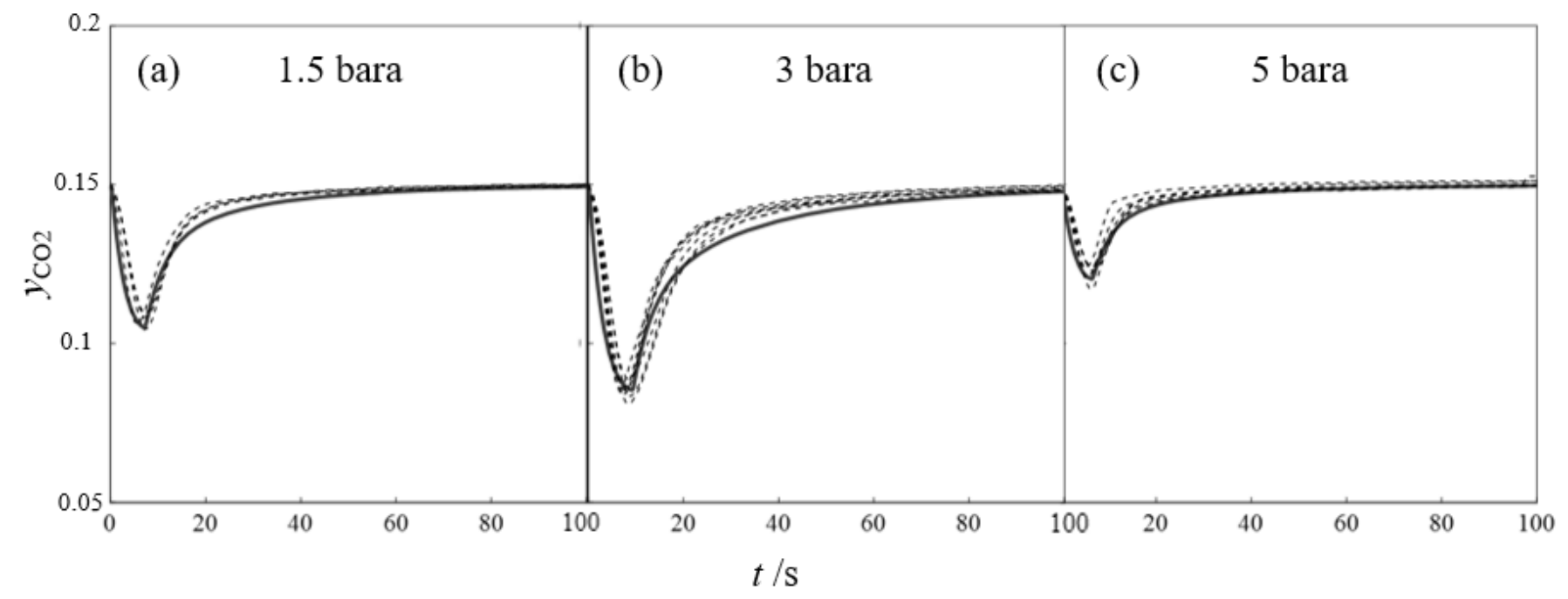

- Model output concentration - - -Experimental data

Figure 11 Modelled vs experimental results for carbonation of $0.5 \mathrm{~g}$ of $\mathrm{CaO}(355-425 \mu \mathrm{m})$ at $650{ }^{\circ} \mathrm{C}$ for three different pressures: 1.5 bara (a), 3 bara (b) and 5 bara (c) with fluidizing gas consisting of $15 \mathrm{vol} \% \mathrm{CO}_{2}$ balanced with $\mathrm{N}_{2} . U / U_{\mathrm{mf}}=3\left(55 \mathrm{ml} \mathrm{s}^{-1} @ S A T P\right) . k_{\mathrm{s} 0}=6.03$ x $10^{-10} \mathrm{~m}^{4} \mathrm{~mol}^{-1} \mathrm{~s}^{-1}$ and $D_{\mathrm{p} 0}=1.81 \times 10^{-13} \mathrm{~m}^{2} \mathrm{~s}^{-1}$.
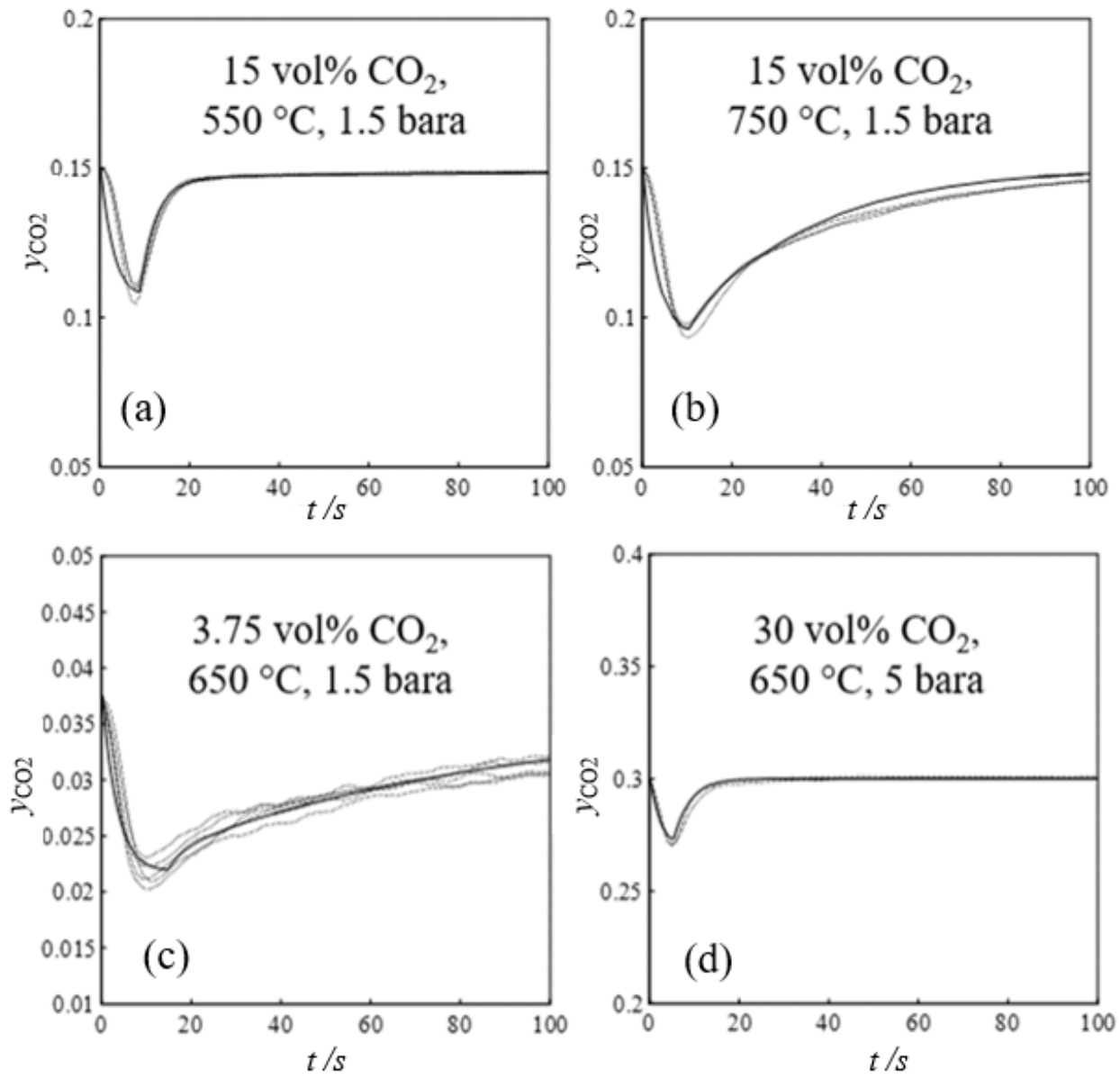

-Model output concentration - - -Experimental data

Figure 12 Modelled vs experimental results for carbonation of Longcliffe-derived CaO (0.5 g) at $550{ }^{\circ} \mathrm{C}$ and 1.5 bara (a), 15 vol\% $\mathrm{CO}_{2}$ at $750{ }^{\circ} \mathrm{C}$ and 1.5 bara (b), at $650{ }^{\circ} \mathrm{C}, 1.5$ bara under $3.75 \mathrm{vol} \% \mathrm{CO}_{2}(\mathrm{c})$ and at $650{ }^{\circ} \mathrm{C}, 5$ bara under 30 vol $\% \mathrm{CO}_{2}(11 \mathrm{~d}) . U / U_{\mathrm{mf}}=3$ (55 ml s-1 @SATP). 


$$
P_{\mathrm{CO}_{2} \text {, max }}=\frac{k_{\mathrm{S}}\left(P_{\left.\mathrm{CO}_{2}-P_{\mathrm{CO}_{2} \mathrm{eq}}\right)}\right.}{k_{\mathrm{s} 0}}+P_{\mathrm{CO}_{2} \mathrm{eq}}
$$

Eq 31 was then substituted back into eq 30 to obtain a zero-order reaction rate equation for conditions involving high $\mathrm{CO}_{2}$ partial pressures.

To obtain the product layer diffusivity $\left(D_{\mathrm{p}}\right)$, a different approach was used. Both the reduced form (eq 29/30) and

the full random pore model (eq 13) were implemented into the reactor model. As soon as the maximum drop in $\mathrm{CO}_{2}$ concentration was reached, the reaction equation was switched over from eq 29/30 (depending on the inlet $\mathrm{CO}_{2}$ partial pressure) to eq 13. $D_{\mathrm{p}}$ was then obtained by determining the value of $D_{\mathrm{p}}$ which gave the smallest RSS between the model output and the experimental data.

Modelled Activation Energies. Table 4 shows the fitted product layer diffusivities, final values for the rate constants, the modelled $\mathrm{CaO}$ conversion and the experimentally observed conversions (calculated with eq 20). One point to note is that the values of the surface rate constant, $k_{s} 0$ fell in line with the data presented by Bhatia and Perlmutter. ${ }^{1}$ The authors obtained values between 3.7 and $6.3 \times 10^{-10} \mathrm{~m}^{4} \mathrm{~mol}^{-}$ ${ }^{1} \mathrm{~s}^{-1}$ for a temperature range of 550 to $725^{\circ} \mathrm{C}$ in a $10 \mathrm{vol} \%$ $\mathrm{CO}_{2}$ atmosphere. The surface rate constants obtained from the two-phase model were also compared to experimental results where a complex reactor model was not used, and the entire bed was simply modelled as a CSTR in an Arrhenius plot (Figure 9).

The slope in Figure 8 represents the activation energy. Using all the available data, eq 32 was derived to characterise the surface rate constant as a function of temperature.

$$
k_{\mathrm{s} 0}=k_{0} \mathrm{e}^{-\frac{E_{\mathrm{a}}}{R T}}=3 \times 10^{-7} \mathrm{e}^{-\frac{47700}{R T}}\left[\mathrm{~m}^{4} \mathrm{~mol}^{-1} \mathrm{~s}^{-1}\right]
$$

Interestingly, the activation energy (determined using the Student's t-test statistical analysis with (n-2) degrees of freedom and a 95\% confidence interval) obtained from the model, $48 \pm 17 \mathrm{~kJ} \mathrm{~mol}^{-1}$ was found to be very similar, despite the slightly lower values for the rate constants, to the activation energy obtained through experimental work assuming that the reactor was a simple CSTR. This confirms that a complex model is not necessarily required to obtain reaction kinetics in this instance. This values also agrees well with Nouri and Ebrahim ${ }^{34}\left(46 \mathrm{~kJ} \mathrm{~mol}^{-1}\right)$ as well as Dedman and Owen ${ }^{35}$ (39 kJ mol-1). However, this activation energy differs from the activation energies obtained by other authors. Sun et al..$^{9}$ obtained $29 \mathrm{~kJ} \mathrm{~mol}^{-1}$ and Grasa et al. ${ }^{10} \mathrm{a}$ value of $20.3 \mathrm{~kJ} \mathrm{~mol}^{-1}$ while Bhatia and Perlmutter ${ }^{1}$ and Dennis and Hayhurst ${ }^{36}$ reported no activation energy. This discrepancy is likely a result of different operating conditions, reaction system and limestone.

The results show that there is a large variation in the values for the initial fitted product layer diffusivities, $D_{\mathrm{p}}$. However, since the product layer diffusivity should only be a function of temperature and not the partial pressures, the initial values were averaged for each set of temperatures to obtain an averaged value for the diffusivity, $D_{\mathrm{p} 0}$. These averaged values were found to have similar orders of magnitude to the product layer diffusivities predicted by Sun et al. ${ }^{11} \mathrm{de}-$ spite the different operating conditions and sorbents (Figure 10). Sun et al. ${ }^{11}$ used the random pore model to fit their experimental results from carbonating different sorbents under 80-100 vol\% $\mathrm{CO}_{2}$ (balanced in nitrogen) under atmospheric pressures inside a TGA. The authors tested Straussburg limestone as opposed to Longcliffe limestone which was used in this work.

The activation energy obtained in this work, $196 \pm 43 \mathrm{~kJ}$ mol-1 $^{-1}$ overlaps with the values obtained by Sun et al. ${ }^{11}$ for their limestone $\left(214 \mathrm{~kJ} \mathrm{~mol}^{-1}\right)$. The results also agree with the activation energy reported by Lee et al. ${ }^{8}\left(189 \mathrm{~kJ} \mathrm{~mol}{ }^{-1}\right)$ and also that obtained by Bhatia and Perlmutter $^{1}(179.2 \mathrm{~kJ}$ $\mathrm{mol}^{-1}$ ). Eq 33 shows the full expression for the product layer diffusivity as a function of temperature where $D_{o}$ is the preexponential factor.

$$
D_{\mathrm{p} 0}=D_{0} \mathrm{e}^{-\frac{E_{\mathrm{a}}}{R T}}=0.018 \mathrm{e}^{-\frac{196000}{R T}}\left[\mathrm{~m}^{2} \mathrm{~s}^{-1}\right]
$$

Modelled Concentration Profiles. Figures 11a, b and c compare the carbonation reaction profile from the model with the experimental data at $650{ }^{\circ} \mathrm{C}$ for total pressures of $1.5,3$ and 5 bara with $15 \mathrm{vol}_{\%} \mathrm{CO}_{2}$. The overall match is very good but there are some slight discrepancies in the first few seconds of the reaction. The experimental results are characterised by an initial nucleation stage, a phenomenon observed by Bhatia et al. ${ }^{1}$ where the gas reacts slowly as crystals of calcite begin to form which causes the sigmoidal shape in the conversion-time profile for carbonation. This introductory stage was then followed by a much more rapid kinetically-controlled stage, where the $\mathrm{CO}_{2}$ concentration experiences a steep drop. The reactor model did not take into account this nucleation stage and therefore immediately starts with a sharp decline in gas concentration which resulted in these deviations. The combination of this initial nucleation stage and the fact that the surface rate constants and product layer diffusivities were averaged led to the slight differences in modelled predicted and experimentally measured $\mathrm{CaO}$ conversions shown in Table 4. Despite the cause of these disparities, the model computes aa reasonable estimate of the conversions.

At the lower temperatures, the product layer diffusion becomes more limiting as these conditions favour carbonation conditions over the calcination conditions. The product layer more rapidly becomes rate limiting and hence the resistance to product layer diffusion increases. This results in a smaller conversion and the $\mathrm{CO}_{2}$ concentration in the reaction profile recovers more quickly. Conversely, at the higher temperatures, the product layer diffusion is more rapid. As the temperature increases, there is a greater competition between carbonation and calcination which makes it more difficult for the $\mathrm{CaCO}_{3}$ product layer to fully form. This results in a slow but gradual carbonation reaction and higher conversions.

It can be seen in Figure 12c and $12 \mathrm{~d}$ that as the inlet $\mathrm{CO}_{2}$ partial pressure increases, the $\mathrm{CaO}$-sorbent is subject to a larger driving force, resulting in a faster rate of reaction and greater build-up of product layer. This leads to increased solid-state diffusion resistance and hence reduced rate of diffusivity. Consequently, the reaction finishes more quickly 
at the under higher partial pressures of $\mathrm{CO}_{2}$. This is shown clearly by the shape of the reaction profiles.

Figures 12a-d demonstrate clearly that the two-phase model fits the experimental data well over a wide range of operating conditions. The good agreement between the model and the experimental results suggests that the model has the potential to be adjusted to simulate similar solid looping and $\mathrm{CO}_{2}$ capture processes.

\section{CONCLUSIONS}

In this paper, a dynamic reactor model was developed and used to determine the kinetics of the reaction between $\mathrm{CaO}$ with $\mathrm{CO}_{2}$. The reactor model was constructed based on two-phase theory and coded as a system of ordinary differential equations using MATLAB. The reactor model considers bubble growth, changing molar flow rates, and assumes that the reaction only occurs in the particulate phase. The random pore model, which was originally developed by Bhatia and Perlmutter ${ }^{1}$ was used as the rate equation. The random model was split into two forms: One to describe the kinetically-controlled step and the other to describe the diffusion-controlled step of carbonation. The surface rate constant and product layer diffusivity were obtained by fitting the model to experimental data for carbonation experiments in a $3 \mathrm{~kW}$ e pressurised fluidised-bed reactor by minimizing the residual sum of squares. A good fit was found for each operating condition, and an activation energy was calculated using an Arrhenius plot to give $48 \pm 17 \mathrm{~kJ} \mathrm{~mol}^{-1}$. This value matched the activation energy obtained directly from the experimental results and was in agreement with some of the reported activation energies found in the literature. The activation energy for the product layer diffusivity was found to be $196 \pm 43 \mathrm{~kJ} \mathrm{~mol}^{-1}$, which also agrees well with those reported in literature despite the different methods to obtaining them, including the extension to pressurised reactions reported herein. The development of this reactor model makes it possible to model commercial-scale carbonators and can be extended onto other gas-solid reaction process.

\section{ASSOCIATED CONTENT}

Supporting Information. Additional equations and MATLAB code of the model. This material is available free of charge via the Internet at http://pubs.acs.org.

\section{AUTHOR INFORMATION}

\section{Corresponding Author}

*E-mail: jgy108@imperial.ac.uk

*E-mail: p.fennell@imperial.ac.uk

\section{ORCID:}

Joseph G. Yao: 0000-0001-9386-1974

Paul S. Fennell: 0000-0002-6001-5285

\section{Notes}

The authors declare no competing financial interest. Requests for data should be send to https://www.imperial.ac.uk/people/p.fennell

\section{ACKNOWLEDGMENT}

This work was supported by the Engineering and Physical Sciences Research Council (EPSRC) through a doctoral training grant for JGY, by Calix Limited and the Department of Energy \& Climate Change (DECC). The authors would also like to acknowledge Dr. Stuart Scott, Lecturer at the University of Cambridge for his Numerical Methods course material upon which the initial model was based. The Joint Bioenergy Institute is thanked for assisting with funding for PSF's stay. Any requests for data can be made through www.imperial.ac.uk/people/p.fennell.

\section{NOMENCLATURE}

\begin{tabular}{|c|c|c|}
\hline Symbol & Description & Units \\
\hline$A$ & Cross-sectional area of bed & $m^{2}$ \\
\hline$C_{\mathrm{CO} 2}$ & Concentration of $\mathrm{CO}_{2}$ & $\mathrm{~mol} \mathrm{~m}^{-3}$ \\
\hline$C_{\mathrm{CO} 2 \mathrm{eq}}$ & $\begin{array}{l}\text { Concentration of } \mathrm{CO}_{2} \text { at equilib- } \\
\text { rium }\end{array}$ & $\mathrm{mol} \mathrm{m}^{-3}$ \\
\hline$C_{\mathrm{m}}$ & Measure concentration & $\mathrm{mol} \mathrm{m}^{-3}$ \\
\hline$C_{\mathrm{t}}$ & 'True' concentration & $\mathrm{mol} \mathrm{m}^{-3}$ \\
\hline$D_{0}$ & $\begin{array}{l}\text { Product layer diffusion coefficient } \\
\text { pre-exponential factor }\end{array}$ & $m^{2} s^{-1}$ \\
\hline$D_{\mathrm{AB}}$ & Bulk diffusivity of gas $A$ in $B$ & $m^{2} s^{-1}$ \\
\hline$D_{\text {eff }}$ & Effective diffusivity & $m^{2} s^{-1}$ \\
\hline$D_{\mathrm{k}}$ & Knudsen diffusivity & $m^{2} s^{-1}$ \\
\hline$D_{\mathrm{P}}$ & $\begin{array}{l}\text { Fitted product layer diffusion coef- } \\
\text { ficient }\end{array}$ & $m^{2} s^{-1}$ \\
\hline$D_{\mathrm{p} 0}$ & $\begin{array}{l}\text { Averaged product layer diffusion } \\
\text { coefficient }\end{array}$ & $m^{2} s^{-1}$ \\
\hline$d_{\mathrm{b}}$ & Bubble diameter & $m$ \\
\hline$d_{\mathrm{b} 0}$ & Initial bubble diameter & $m$ \\
\hline$d_{\mathrm{bm}}$ & $\begin{array}{l}\text { Limiting size of bubble diameter in } \\
\text { a deep bed }\end{array}$ & $m$ \\
\hline$d_{\mathrm{p}}$ & Mean diameter of particle & $m$ \\
\hline$d_{\mathrm{R}}$ & Diameter of quartz liner & $m$ \\
\hline$E_{\mathrm{a}}$ & Activation energy & $\mathrm{kJ} \mathrm{mol}^{-1}$ \\
\hline$g$ & Acceleration due to gravity & $m s^{-2}$ \\
\hline$H_{\mathrm{f}}$ & Height of fluidised bed & $m$ \\
\hline$H_{\mathrm{mf}}$ & $\begin{array}{l}\text { Height of bed at minimum fluidisa- } \\
\text { tion }\end{array}$ & $m$ \\
\hline$k_{0}$ & $\begin{array}{l}\text { Surface rate constant pre-exponen- } \\
\text { tial factor }\end{array}$ & $\begin{array}{l}m^{4} \mathrm{~mol}^{-} \\
{ }^{1} \mathrm{~s}^{-1}\end{array}$ \\
\hline$k_{\mathrm{i}}$ & Pseudo-intrinsic rate constant & $m s^{-1}$ \\
\hline$k_{\mathrm{s}}$ & Fitted surface rate constant & $\begin{array}{l}m^{4} \mathrm{~mol}^{-} \\
{ }^{1} \mathrm{~s}^{-1}\end{array}$ \\
\hline$k_{\mathrm{s} 0}$ & Averaged surface rate constant & $\begin{array}{l}\mathrm{m}^{4} \mathrm{~mol}^{-} \\
{ }^{1} \mathrm{~s}^{-1}\end{array}$ \\
\hline$L_{0}$ & $\begin{array}{l}\text { Initial total length of pore system } \\
\text { per unit volume }\end{array}$ & $m m^{-3}$ \\
\hline$M_{\mathrm{i}}$ & Molecular weight of component i & $g \mathrm{~mol}^{-1}$ \\
\hline$n_{\mathrm{N} 2}$ & Molar flow rate of nitrogen & $\mathrm{mol} \mathrm{s}^{-1}$ \\
\hline$P$ & System Pressure & $\mathrm{Pa}$ \\
\hline
\end{tabular}




\begin{tabular}{|c|c|c|}
\hline$P_{\mathrm{CO} 2}$ & Partial pressure of $\mathrm{CO}_{2}$ & $\mathrm{~Pa}$ \\
\hline$P_{\mathrm{CO} 2, \max }$ & Transition partial pressure of $\mathrm{CO}_{2}$ & $P a$ \\
\hline$P_{\mathrm{CO} 2, \max (\text { guess })}$ & Initial guess for $P_{C O 2, \max }$ & $P a$ \\
\hline$P_{\text {CO2eq }}$ & Equilibrium vapor pressure of $\mathrm{CO}_{2}$ & $P a$ \\
\hline$Q_{\mathrm{b}}$ & $\begin{array}{l}\text { Net volumetric flow of gas through } \\
\text { bubble }\end{array}$ & $m^{3} s^{-1}$ \\
\hline$R$ & Molar gas constant & $\begin{array}{l}\text { kJ mol-1 } \\
K^{-1}\end{array}$ \\
\hline$r$ & Observed rate of reaction & $s^{-1}$ \\
\hline$r_{\mathrm{CO} 2}$ & Rate of $\mathrm{CO}_{2}$ consumption & $\mathrm{mol} \mathrm{s}^{-1}$ \\
\hline$S_{\mathrm{g}}$ & Specific surface area & $m^{2} g^{-1}$ \\
\hline$S_{0}$ & $\begin{array}{l}\text { Initial specific surface area of CaO } \\
\text { following decomposition of its pre- } \\
\text { cursor }\end{array}$ & $m^{2} m^{-3}$ \\
\hline$T$ & Time & $s$ \\
\hline$T$ & Absolute temperature & $K$ \\
\hline$U$ & Superficial velocity of fluidizing gas & $m s^{-1}$ \\
\hline$U_{\mathrm{b}}$ & Bubble velocity & $m s^{-1}$ \\
\hline$U_{\mathrm{mf}}$ & Minimum fluidisation velocity & $m s^{-1}$ \\
\hline$V_{\mathrm{b}}$ & Bubble volume & $m^{3}$ \\
\hline$V_{\mathrm{fb}}$ & Volume of freeboard & $m^{3}$ \\
\hline$V_{\mathrm{p}}$ & Total pore volume & $m^{3} g^{-1}$ \\
\hline$V_{\mathrm{pl}}$ & Volume of plenum chamber & $m^{3}$ \\
\hline$w_{\mathrm{CaO}}$ & Weight of $\mathrm{CaO}$ & $g$ \\
\hline$X$ & Conversion & \\
\hline$y_{\mathrm{i}}$ & $\begin{array}{l}\text { Mole fraction of component } \mathrm{i} \text { in gas } \\
\text { phase }\end{array}$ & \\
\hline$y_{\mathrm{bco} 2}$ & $\begin{array}{l}\text { Mole fraction of } \mathrm{CO}_{2} \text { in bubble } \\
\text { phase }\end{array}$ & \\
\hline$y_{\text {pco2 }}$ & $\begin{array}{l}\text { Mole fraction of } \mathrm{CO}_{2} \text { in particulate } \\
\text { phase }\end{array}$ & \\
\hline$Z$ & $\begin{array}{l}\text { Ratio of volume of solid phase of } \\
\mathrm{CaCO}_{3} \text { to } \mathrm{CaO}\end{array}$ & \\
\hline
\end{tabular}

Greek Symbols

\begin{tabular}{|c|c|c|}
\hline$\beta$ & $\begin{array}{l}\text { Modified biot modulus in the ran- } \\
\text { dom pore model }\end{array}$ & \\
\hline$\varepsilon_{0}$ & $\begin{array}{l}\text { Initial particle porosity following } \\
\text { decomposition of CaO precursor }\end{array}$ & \\
\hline$\varepsilon_{\mathrm{AB}}$ & $\begin{array}{l}\text { Maximum attractive energy be- } \\
\text { tween two molecules }\end{array}$ & $J$ \\
\hline$\varepsilon_{\mathrm{b}}$ & Bubble fraction & \\
\hline$\varepsilon_{\mathrm{mf}}$ & Voidage in particulate phase & \\
\hline$\eta$ & Effectiveness factor & \\
\hline$\mu$ & Dynamic viscosity of fluidizing gas & $N s m^{-2}$ \\
\hline$v$ & $\begin{array}{l}\text { Kinematic viscosity of fluidizing } \\
\text { gas }\end{array}$ & $N s m^{-2}$ \\
\hline$v_{0}(r)$ & Pore volume distribution function & \\
\hline$\rho_{\mathrm{CaO}}$ & Density of Calcium Oxide & $\mathrm{kg} \mathrm{m}^{-3}$ \\
\hline
\end{tabular}

$\begin{array}{lll}\sigma_{\mathrm{AB}} & \text { Collision diameter } & m \\ \tau & \text { Tortuosity factor } & \\ \tau_{\mathrm{fb}} & \text { Mixing time constant in freeboard } & s \\ \tau_{\mathrm{mi}} & \begin{array}{l}\text { Response/mixing time of reactor } \\ \text { and analyser }\end{array} & s \\ \tau_{\mathrm{pl}} & \begin{array}{l}\text { Mixing time constant in plenum } \\ \text { chamber }\end{array} & s \\ \phi & \text { Thiele modulus } \\ \psi & \text { Structure parameter in random } \\ & \text { pore model } & \\ \Omega^{(1,5)^{*}} & \text { Reduced form of Collision integral }\end{array}$

\section{REFERENCES}

1. Bhatia, S. K.; Perlmutter, D. D., Effect of the Product Layer on the Kinetics of the $\mathrm{CO}_{2}$-Lime Reaction. AIChE Journal 1983, 29, (1), 79-86.

2. Boot-Handford, M. E.; Abanades, J. C.; Anthony, E. J.; Blunt, M. J.; Brandani, S.; Mac Dowell, N.; Fernandez, J. R.; Ferrari, M. C.; Gross, R.; Hallett, J. P.; Haszeldine, R. S.; Heptonstall, P.; Lyngfelt, A.; Makuch, Z.; Mangano, E.; Porter, R. T. J.; Pourkashanian, M.; Rochelle, G. T.; Shah, N.; Yao, J. G.; Fennell, P. S., Carbon capture and storage update. Energy \& Environmental Science 2014, 7, (1), 130-189.

3. Florin, N. H.; Blamey, J.; Fennell, P. S., Synthetic $\mathrm{CaO}$-Based Sorbent for $\mathrm{CO}_{2}$ Capture from Large-Point Sources. Energy \& Fuels 2010, 24, (8), 4598-4604.

4. Abanades, J. C.; Alvarez, D., Conversion limits in the reaction of CO2 with lime. Energy \& Fuels 2003, 17, (2), 308315.

5. Al-Jeboori, M. J.; Fennell, P. S.; Nguyen, M.; Peng, K., Effects of Different Dopants and Doping Procedures on the Reactivity of $\mathrm{CaO}$-based Sorbents for $\mathrm{CO}_{2}$ Capture. Energy \& Fuels 2012, 26, (11), 6584-6594.

6. Ives, M.; Mundy, R. C.; Fennell, P. S.; Davidson, J. F.; Dennis, J. S.; Hayhurst, A. N., Comparison of Different Natural Sorbents for Removing $\mathrm{CO}_{2}$ from Combustion Gases, as Studied in a Bench-Scale Fluidized Bed. Energy \& Fuels 2008, 22, (6), 3852-3857.

7. Blamey, J.; Paterson, N. P. M.; Dugwell, D. R.; Fennell, P. S., Mechanism of Particle Breakage during Reactivation of $\mathrm{CaO}$-Based Sorbents for $\mathrm{CO}_{2}$ Capture. Energy \& Fuels 2010, 24, (8), 4605-4616.

8. Lee, D. K., An apparent kinetic model for the carbonation of calcium oxide by carbon dioxide. Chemical Engineering Journal 2004, 100, (1-3), 71-77.

9. Sun, P.; Grace, J. R.; Lim, C. J.; Anthony, E. J., Determination of intrinsic rate constants of the $\mathrm{CaO}-\mathrm{CO}_{2}$ reaction. Chemical Engineering Science 2008, 63, (1), 47-56. 10. Grasa, G.; Murillo, R.; Alonso, M.; Abanades, J. C., Application of the Random Pore Model to the Carbonation Cyclic Reaction. AIChE Journal 2009, 55, (5), 1246-1255.

11. Sun, P.; Grace, J. R.; Lim, C. J.; Anthony, E. J., A discrete-pore-size-distribution-based gas-solid model and its application to the $\mathrm{CaO}+\mathrm{CO}_{2}$ reaction. Chemical Engineering Science 2008, 63, (1), 57-70.

12. Levenspiel, O., Chemical Reaction Engineering 3rd edition. Wiley: New York, 1972. 
13. Szekely, J.; Evans, J. W.; Sohn, H. Y., Gas-solid reactions. Academic Press: New York, 1976.

14. Stendardo, S.; Foscolo, P. U., Carbon dioxide capture with dolomite: A model for gas-solid reaction within the grains of a particulate sorbent. Chemical Engineering Science 2009, 64, (10), 2343-2352.

15. Lu, A.-H.; Dai, S., Porous Materials for Carbon Dioxide Capture. Springer-Verlag: Heidelberg, New York, Dordercht, London, 2014.

16. Khoshandam, B.; Kumar, R. V.; Allahgholi, L., Mathematical modeling of $\mathrm{CO}_{2}$ removal using carbonation with CaO: The grain model. Korean Journal of Chemical Engineering 2010, 27, (3), 766-776.

17. Bhatia, S. K.; Perlmutter, D. D., A Random Pore Model for Fluid-Solid Reactions .1. Isothermal, Kinetic Control. AIChE Journal 1980, 26, (3), 379-386.

18. Bhatia, S. K.; Perlmutter, D. D., A Random Pore Model for Fluid-Solid Reactions .2. Diffusion and Transport Effects. AIChE Journal 1981, 27, (2), 247-254.

19. Nouri, S. M. M.; Ebrahim, H. A.; NaserNejad, B., A modified random pore model for carbonation reaction of calcium oxide with carbon dioxide. Hemijska Industrija 2015, 69, (2), 209-217.

20. Scott, S. A., Numerical Methods in Chemical Engineering Lecture Notes: Chapter 8. Cambridge University 2006, 14.

21. Zhang, Z.; Hills, T.; Scott, S. A.; Fennell, P. S., Spouted Bed Reactor for kinetic measurements of reduction of $\mathrm{Fe}_{2} \mathrm{O}_{3}$ in a $\mathrm{CO}_{2} / \mathrm{CO}$ atmosphere Part I: atmospheric pressure measurements and equipment commisisioning. Chemical Engineering Research \& Design 2016.

22. Toomey, R.; Johnstone, H., Gaseous fluidization of solid particles. Chemical Engineering Progress 1952, 48, (5), 220-226.

23. Kunii, D.; Levenspiel, O., Fluidization engineering. Butterworth-Heinemann: 1991; p 491.

24. Mori, S.; Wen, C. Y., Estimation of Bubble Diameter in Gaseous Fluidized-Beds. AIChE Journal 1975, 21, (1), 109-115.
25. J.F. Davidson; Harrison, D., Fluidised Particles. Cambridge University Press: New York, 1963.

26. Johnson, R. W., Handbook of Fluid Dynamics. CRC Press: 1998; p 1952.

27. Alvarez, D.; Abanades, J. C., Determination of the critical product layer thickness in the reaction of $\mathrm{CaO}$ with $\mathrm{CO}_{2}$. Industrial \& Engineering Chemistry Research 2005, 44, (15), 5608-5615.

28. Ebrahim, H. A., Application of Random-Pore Model to SO2 Capture by Lime. Industrial \& Engineering Chemistry Research 2010, 49, (1), 117-122.

29. Fennell, P. S.; Dennis, J. S.; Hayhurst, A. N., The order with respect to oxygen and the activation energy for the burning of an anthracitic char in 02 in a fluidised bed, as measured using a rapid analyser for $\mathrm{CO}$ and $\mathrm{CO}_{2}$. Proceedings of the Combustion Institute 2009, 32, (2), 20512058.

30. Bird, R. B.; Stewart, W. E.; Lightfoot, E. N., Transport Phenomena Second Edition. John Wiley \& Sons, Inc.: US, 2002.

31. Satterfield, C. N., Heterogeneous Catalysis in Practice. McGraw-Hill: New York: New York, 1980.

32. Klein, M.; Smith, F. J., Table of Collision Integrals for the $(\mathrm{m}, 6)$ Potential Function for 10 Values of $\mathrm{m}^{*}$. Journal of Research of the National Bureau of Standards- A. Physics and Chemistry 1968, 72A, (4).

33. Yu, F. C.; Fan, L. S., Kinetic Study of High-Pressure Carbonation Reaction of Calcium-Based Sorbents in the Calcium Looping Process (CLP). Industrial \& Engineering Chemistry Research 2011, 50, (20), 11528-11536.

34. Nouri, S. M. M.; Ale Ebrahim, H., Kinetic study of $\mathrm{CO} 2$ reaction with $\mathrm{CaO}$ by a modified random pore model. In Polish Journal of Chemical Technology, 2016; Vol. 18, p 93. 35. Dedman, A.; Owen, A., Calcium cyanamide synthesis. Part 4.-The reaction $\mathrm{CaO}+\mathrm{CO}_{2}=\mathrm{CaCO}_{3}$. Transactions of the Faraday Society 1962, 58, 2027-2035.

36. Dennis, J. S.; Hayhurst, A. N., The Effect of Co2 on the Kinetics and Extent of Calcination of Limestone and Dolomite Particles in Fluidized-Beds. Chemical Engineering Science 1987, 42, (10), 2361-2372. 